\title{
Carbon species solvated in molten carbonate electrolyser cell from first-principles simulations
}

\author{
Antoine Carof ${ }^{\mathrm{a}, 1}$, François-Xavier Coudert ${ }^{\mathrm{b}}$, Dario Corradini ${ }^{\mathrm{a}, 2}$, Dominika \\ Lesnicki $^{\mathrm{b}, 3}$, Elsa Desmaele ${ }^{\mathrm{a}}$, Rodolphe Vuilleumier ${ }^{\mathrm{a}, *}$ \\ ${ }^{a}$ PASTEUR, Département de chimie, École normale supérieure, PSL University, Sorbonne \\ Université, CNRS, 75005 Paris, France \\ ${ }^{b}$ Chimie Paris Tech, PSL University, CNRS, Institut de Recherche de Chimie Paris, 75005 \\ Paris, France
}

\begin{abstract}
We study the solvation of molecules and ions that are key in the context of Molten Carbonate Electrolyser Cells using first-principles simulations. Focusing on the electroreduction of $\mathrm{CO}_{2}$ to $\mathrm{CO}$ in a molten carbonate medium, we investigate the solvation of both the reactant $\mathrm{CO}_{2}$ and the product $\mathrm{CO}$ in the eutectic $\mathrm{LiKCO}_{3}$ (containing $62 \% \mathrm{Li}_{2} \mathrm{CO}_{3}, 38 \% \mathrm{~K}_{2} \mathrm{CO}_{3}$ ). $\mathrm{CO}_{2}$ is found to spontaneously react with the carbonate ions to form the transient pyrocarbonate species, $\mathrm{C}_{2} \mathrm{O}_{5}^{2-}$. To investigate the similar reaction that could occur with $\mathrm{CO}$ and $\mathrm{CO}_{3}^{2-}$ to form an oxalate, we simulated that species and found it to be stable in the melt, supporting this hypothesis. We further present the solvation of $\mathrm{O}^{2-}$, finding that it shows preferential formation of a complex with four lithium cations. Estimates of the diffusion coefficients of these species are then reported, showing that $\mathrm{CO}$ has the faster diffusion of all the molecules and ions studied.
\end{abstract}

Keywords: Molten carbonate, first-principles simulation, solvation properties

\section{Introduction}

Molten carbonates are nowadays used in many applications. [1] For instance, molten carbonate fuel cells (MCFC) can produce electricity in the MW range with long term stability [2]. Moreover, because MCFC consume $\mathrm{CO}_{2}$ at the cathode side and release $\mathrm{CO}_{2}$ at the anode side, they have been proposed to combine this electricity production capability with the capture and the concentration of $\mathrm{CO}_{2}$ out of exhaust gas from steel mills [3-5]. Alternatively, the high

\footnotetext{
* Corresponding author

Email address: rodolphe.vuilleumier@ens.fr (Rodolphe Vuilleumier)

${ }^{1}$ Present address: Université de Lorraine, CNRS, LPCT, F-54000 Nancy, France

${ }^{2}$ Present address: American Physical Society, Ridge, NY 11961, USA

${ }^{3}$ Present address: Sorbonne Université, CNRS, Physico-Chimie des électrolytes et Nanosystèmes Interfaciaux, F-75005 Paris, France
} 
solubility of $\mathrm{CO}_{2}$ in molten carbonates is a possible path to perform carbon capture and utilization (CCU) by electroreduction of $\mathrm{CO}_{2}$ in molten carbonate electrolyser cells (MCEC) [6-10]. The reduction of $\mathrm{CO}_{2}$ in MCEC into amorphous carbon has been well documented and the conversion of $\mathrm{CO}_{2}$ to $\mathrm{CO}$ or even $\mathrm{CH}_{4}$ has also been evidenced recently [11-13], thus adding another opportunity for carbon capture and utilisation using carbonate melts.

Optimizing the conditions for an efficient electroreduction of $\mathrm{CO}_{2}$ in MCEC, for example by tuning the melt temperature or the composition, calls for a better understanding of the microscopic processes involved. In particular, there is need to better understand the speciation of the carbon species and their solvation properties in the melt. Cyclic voltametry [12] has shown that the mechanism of electroreduction of $\mathrm{CO}_{2}$ in $\mathrm{CO}$ is complex and involves the formation of several other species during the reaction. However, the exact nature of these species remains unclear and cyclic voltametry provides only limited microscopic information about these species.

Several recent studies have highlighted the power of computational approaches for the understanding of these complex systems, and a number of of molecular dynamics simulation of molten carbonates have been reported [14-20]. Molecular dynamics simulations can provide a picture of molecular mechanisms and can accurately predict physico-chemical properties, especially in high temperature and high pressure conditions where experiments are hard to perform.

Molecular dynamics simulations exist in two different flavours: first-principles molecular dynamics (FPMD) and force field based molecular dynamics (FFMD). In the latter, energy and nuclear forces are calculated at each time step via a force field function. This method is very efficient numerically and can be used to perform molecular dynamics simulation in large systems, but it requires the design and parametrization of a specific force field describing the interactions between the molecular components of the system. On the other hand, FPMD provides an alternative route by computing on the fly the forces acting on the atoms using an explicit description of the electrons via quantum chemistry methods (e.g. DFT). [21] FPMD simulations are thus free of force field parametrization and have the further advantage of being able to directly describe chemical phenomena (e.g. bond breaking and forming); however they have a much higher computational cost than classical methods. In the context of modelling molten carbonate, FPMD simulations showed in particular that the solvation of $\mathrm{CO}_{2}$ within $\mathrm{CaCO}_{3}$ at geological conditions ( $\mathrm{T}=1773 \mathrm{~K}$ and $\mathrm{GPa}$ pressure) leads to the formation of a transient species, the pyrocarbonate anion $\mathrm{C}_{2} \mathrm{O}_{5}^{2-}$. [15] This reactivity of $\mathrm{CO}_{2}$ with the carbonate ions has consequences both on the solubility of $\mathrm{CO}_{2}$ and on its transport properties; it could not have been observed in a force field-based simulation. FPMD simulations can also be used in combination with FFMD simulations by building new force fields based on the data obtained during the FPMD simulation, and then rely on the efficiency of FFMD to study large systems. This strategy has been successfully applied to the description of alkaline-earth molten carbonates and molten carbonates of lithium, sodium and potassium $[16,19,20]$, for instance in order to predict the equation of state of liquid $\mathrm{CaCO}_{3}$, its viscosity and its conductivity [14] in good agreement with 
available experiments [22]. However, these first-principles based FFMD do not allow to study the reactivity and the formation/disproportionation of the transient pyrocarbonate anion in $\mathrm{CaCO}_{3}$, underlining the necessity to use FPMD to model the solvation of potentially reactive species such as $\mathrm{CO}_{2}$ or $\mathrm{CO}$ in molten carbonates.

We present here a FPMD study of the solvation of species involved during the $\mathrm{CO}_{2}$ reduction process in the eutectic $(62 \%: 38 \%) \mathrm{LiKCO}_{3}$. Among the different melts presently under investigation to operate in a MCEC, we decided to look specifically at the solvation properties in the eutectic $(62 \% 38 \%) \mathrm{LiKCO}_{3}$ (simply denoted $\mathrm{LiKCO}_{3}$ in the following). This binary mixture has a lower eutectic temperature $(\mathrm{T}=761 \mathrm{~K})$ than its other alkali-carbonates counterparts $\left(\mathrm{T}=771 \mathrm{~K}\right.$ for $42.7 \% 57.3 \% \mathrm{LiKCO}_{3}, \mathrm{~T}=774 \mathrm{~K}$ for $52 \% 48 \% \mathrm{LiNaCO}_{3}$ and $\mathrm{T}=983 \mathrm{~K}$ for $56 \% 44 \% \mathrm{NaKCO}_{3}$ ). The first species are $\mathrm{CO}_{2}$ itself and the corresponding pyrocabonate ion $\mathrm{C}_{2} \mathrm{O}_{5}^{2-}$. Next, we study the end product of the reaction, i.e. CO. It has been proposed in cyclic voltametry experiments that $\mathrm{CO}$ can also react with $\mathrm{CO}_{3}^{2-}$ to form the oxalate anion according to [12]

$$
\mathrm{CO}+\mathrm{CO}_{3}^{2-} \leftrightarrow \mathrm{C}_{2} \mathrm{O}_{4}^{2-} .
$$

The chemical valence of carbon in oxalate is +III, which can then be seen as an intermediate species that can disproportionate into $\mathrm{CO}$ and $\mathrm{CO}_{3}^{2-}$. Finally, a crucial parameter in the efficiency of MCFC and MCEC is the oxoacidity of the melt, which can be tuned through the cation composition. Oxoacidity is characterized by the dissociation constant $K_{\mathrm{D}}$ of $\mathrm{CO}_{3}^{2-}$ :

$$
\mathrm{CO}_{3}^{2-} \leftrightarrow \mathrm{CO}_{2}+\mathrm{O}^{2-}
$$

We therefore studied in detail the solvation of $\mathrm{O}^{2-}$ in the eutectic $\mathrm{LiKCO}_{3}$.

The paper is organized as follows. In section 2 we present the FPMD setup used in this study. Then we present results in section 3 , first discussing the reactivity of $\mathrm{CO}_{2}$ with $\mathrm{CO}_{3}^{2-}$ in section 3.1, then solvation structures in section 3.2 and finally dynamics in section 3.3. We then conclude in section 4 .

\section{Methods}

We studied four different systems, each one consisting of a single molecule or anion $\left(\mathrm{CO}_{2}, \mathrm{C}_{2} \mathrm{O}_{4}^{2-}, \mathrm{CO}\right.$ or $\left.\mathrm{O}^{2-}\right)$ solvated in the eutectic $(62 \% 38 \%) \mathrm{LiKCO}_{3}$ at $T=1000 \mathrm{~K}$ and $P=1 \mathrm{~atm}$, i.e. close to the operating conditions of MCFC/MCEC. In these conditions, the experimental density of molten carbonate is $\rho=1.88$ g.cm ${ }^{-3}[23]$ and we thus placed one solvated species $\left(\mathrm{CO}_{2}\right.$, $\mathrm{C}_{2} \mathrm{O}_{4}^{2-}, \mathrm{CO}$ or $\left.\mathrm{O}^{2-}\right), 158$ lithium atoms (159 for the system that contains $\mathrm{O}^{2-}$ ) , 96 potassium atoms (97 in the case of $\mathrm{O}^{2-}$ ) and $127 \mathrm{CO}_{3}^{2-}$ (126 in the case of $\mathrm{C}_{2} \mathrm{O}_{4}^{2-}$ ) in a cubic box of size $a=22.23 \AA$. Periodic boudary condition are applied in all directions. The initial positions of the atoms were obtained from a classical molecular dynamics simulation of pure $\mathrm{LiKCO}_{3}$ with a force field developed previously in our lab [16] and which was tuned using NPT simulations 
to reproduce the experimental density at $P=1 \mathrm{~atm}$. From a pure $\mathrm{LiKCO}_{3}$ equilibrated configuration, we built the simulation box for the different solvated species: for $\mathrm{CO}$ and $\mathrm{CO}_{2}$, we removed one $\mathrm{CO}_{3}^{2-}$ anion, one lithium cation and one potassium cation, and we added the solvated molecule ( $\mathrm{CO}$ or $\mathrm{CO}_{2}$ instead); for $\mathrm{C}_{2} \mathrm{O}_{4}^{2-}$ we removed two $\mathrm{CO}_{3}^{2-}$ anions, one lithium cation and one potassium cation, and we added $\mathrm{C}_{2} \mathrm{O}_{4}^{2-}$; and for $\mathrm{O}^{2-}$ we removed one $\mathrm{CO}_{3}^{2-}$ and we added the anion $\mathrm{O}^{2-}$. The electroneutrality is thus ensured for each simulation box.

The molecular dynamics (MD) simulations were run in the NVT ensemble, using a velocity-Verlet integrator (with a timestep $\Delta t=0.5 \mathrm{fs}$ ) and a canonical sampling/velocity rescaling $(\mathrm{CSVR})$ thermostat $[24]$ ( with $\left.\tau_{\mathrm{CSVR}}=1 \mathrm{ps}\right)$. The length of trajectories for $\mathrm{CO}_{2}, \mathrm{C}_{2} \mathrm{O}_{4}^{2-}, \mathrm{CO}, \mathrm{O}^{2-}$ is $89 \mathrm{ps}, 60 \mathrm{ps}, 41 \mathrm{ps}$ and 43 ps, respectively. Positions of all atoms are stored at every time step for analysis.

As we aim to study the reactivity and stability of the different solvated molecules in the molten carbonate, we opted for first-principles molecular dynamics where energies and forces are calculated at each time step at a DFT level. We used the software CP2K that employs a hybrid Gaussian plane-wave method (GPW). [25-27] To reduce the number of explicit electrons, core electrons were replaced by Goedecker-Teter-Hutter (GTH) norm-conserving pseudopotentials. [28-30] The remaining valence electrons were projected into a doublezeta valence plus polarisation (DZVP) basis set optimized for molecules for each atom type (C, O, Li and $\mathrm{K})$. [31] A cutoff of $700 \mathrm{Ry}$ was used for the electronic density. We chose the BLYP functional to determine the exchange-correlation interactions $[32,33]$ and the DFT-D3 scheme with a cut-off of $40 \AA$ for the dispersive interactions corrections. [34] This combination of BLYP functional and DFT-D3 correction of dispersive interactions was shown to efficiently reproduce the equation of state of different pure molten carbonate (see Ref. [14, 19, 20]).

We complemented these simulations with four simulations of the isolated species $\mathrm{CO}_{2}, \mathrm{C}_{2} \mathrm{O}_{5}^{2-}, \mathrm{C}_{2} \mathrm{O}_{4}^{2-}$ and $\mathrm{CO}$ at $T=1000 \mathrm{~K}$. Each of these isolated species simulations consisted of one molecule in a cubic box of size $a=$ $22.23 \AA$ with periodic boundary conditions, and was run for 20 ps. All parameters for the isolated species simulations (integrator, thermostat, DFT calculations, basis set and pseudopotentials) are the same as for the liquid-phase simulations. For the the isolated anions $\left(\mathrm{C}_{2} \mathrm{O}_{5}^{2-}, \mathrm{C}_{2} \mathrm{O}_{4}^{2-}\right)$, a uniformly background with charge +2 is added in the simulation box to ensure the electroneutrality.

\section{Results}

\subsection{Reactivity}

We first investigate the stability and the potential reactivity of $\mathrm{CO}_{2}, \mathrm{C}_{2} \mathrm{O}_{5}^{2-}$, $\mathrm{C}_{2} \mathrm{O}_{4}^{2-}, \mathrm{CO}$, and $\mathrm{O}^{2-}$ when they are present in the molten carbonate medium. Different reactions involving these molecules have been suggested in the liter-

ature based on indirect experimental evidence (e.g. the presence of peaks in 
cylic voltammetry experiments [12]), in particular the following reactions with the carbonate anion:

$$
\begin{gathered}
\mathrm{CO}_{2}+\mathrm{CO}_{3}^{2-} \rightarrow \mathrm{C}_{2} \mathrm{O}_{5}^{2-}, \\
\mathrm{CO}+\mathrm{CO}_{3}^{2-} \rightarrow \mathrm{C}_{2} \mathrm{O}_{4}^{2-}, \\
\mathrm{CO}_{3}^{2-} \rightarrow \mathrm{O}^{2-}+\mathrm{CO}_{2} .
\end{gathered}
$$

We thus wanted to determine whether such reactions occur in our firstprinciples MD simulations, but molecules are not intrinsically defined in this kind of simulations. Among different possible criteria to define the molecules from first-principles MD trajectories (i.e. the position of all atoms at a given time), we decided to rely on a simple hysteresis geometrical criterion: a pair of atoms (C-O or $\mathrm{C}-\mathrm{C})$ are connected at time $t$ if their interatomic distance is below $1.7 \AA$ or if they were connected at the previous timestep $t-\Delta t$ and their interatomic distance is still below $1.9 \AA$. These criteria mean that a bond can form only when the interatomic distance is below $1.7 \AA$ and can break only when the interatomic distance becomes larger than $1.9 \AA$. The $1.7 \AA / 1.9$ Avalues were chosen because the radial distribution function of the C-O pair in the bulk $\mathrm{LiKCO}_{3}$ is close to zero between those distances. [16] The hysteris approach allows a smoother behaviour than using only a single criterion and were inspired by the criteria used to define hydrogen bonds in water. [35] Based on these criteria, we built at each time step a $N_{\text {atoms }} \times N_{\text {atoms }}$ connectivity matrix $\mathbb{C}(t)$, with $\mathbb{C}_{i j}(t)=1$ if atoms $i$ and $j$ are connected at time $t$ and $\mathbb{C}_{i j}(t)=0$ otherwise. We then determined the connected components of connectivity matrix $\mathbb{C}(t)$, each of these connected components is a molecule present at time $t$.

By applying this molecule-search analysis to the four MD trajectories, we found that: (i) the $\mathrm{CO}_{2}$ molecule reacts with a carbonate to form a pyrocarbonate anion $\mathrm{C}_{2} \mathrm{O}_{5}^{2-}$ (a detailed analysis of this reaction will be given in the next paragraph), (ii) the carbon monoxide $\mathrm{CO}$ does not react with carbonate anions to form an oxalate during the 41 ps simulation, while the oxalate $\mathrm{C}_{2} \mathrm{O}_{4}^{2-}$ does not dissociate into $\mathrm{CO}$ and $\mathrm{CO}_{3}^{2-}$ during the 60 ps of simulation, and (iii) similarly, none of the $507 \mathrm{CO}_{3}^{2-}$ from the four simulation boxes dissociates into $\mathrm{O}^{2-}$ and $\mathrm{CO}_{2}$ among the 233 ps accumulated from the four simulations, while the anion $\mathrm{O}^{2-}$ remains stable for $41 \mathrm{ps}$ of simulation. The stability of these different solvated species will allow us to present their intra- and intermolecular structure and their dynamical properties in section 3.2 and 3.3, respectively. In the case of the isolated species $\left(\mathrm{CO}_{2}, \mathrm{C}_{2} \mathrm{O}_{5}^{2-}, \mathrm{C}_{2} \mathrm{O}_{4}^{2-}, \mathrm{CO}\right)$, we applied the same methodology and found that they are stable for the 20 ps simulation.

The formation of $\mathrm{C}_{2} \mathrm{O}_{5}^{2-}$ was already observed in $\mathrm{CaCO}_{3}$ at geological condition (high pressure and high temperature $T=1773 \mathrm{~K}$ ), [15] but the present work shows that such a reactivity exists also in the milder conditions of an operating MCFC or MCEC (atmospheric pressure, intermediate temperature $T=1000 \mathrm{~K}$ ). Fig. 1(a) illustrates the presence of $\mathrm{C}_{2} \mathrm{O}_{5}^{2-}$ in the eutectic 
$\mathrm{LiKCO}_{3}$. The kinetics of the formation/dissociation equilibrium of the pyrocarbonate anion affect the diffusion and the electrochemical properties of $\mathrm{CO}_{2}$ solvated in this molten carbonate and the process of MCFC and MCEC. From the MD trajectory, we quantified the stability of $\mathrm{C}_{2} \mathrm{O}_{5}^{2-}$ and Fig. 1(b) shows the cumulative lifetime distribution of both $\mathrm{CO}_{2}$ and $\mathrm{C}_{2} \mathrm{O}_{5}^{2-}$. The lifetime of the transient $\mathrm{C}_{2} \mathrm{O}_{5}^{2-}$ is at maximum half an order of magnitude shorter than that of $\mathrm{CO}_{2}$ (2.5 ps vs $12 \mathrm{ps).} \mathrm{To} \mathrm{extract} \mathrm{the} \mathrm{characteristic} \mathrm{lifetime,} \mathrm{both} \mathrm{distributions}$ were fitted with an exponential function and we obtained $\tau_{\mathrm{CO}_{2}}=2.3 \mathrm{ps}$ and $\tau_{\mathrm{C}_{2} \mathrm{O}_{5}^{2-}}=0.6 \mathrm{ps}$. These lifetimes are of the same order of magnitude as the one calculated in the geological $\mathrm{CaCO}_{3}\left(0.88\right.$ ps for $\mathrm{CO}_{2}$ and 0.38 ps for $\left.\mathrm{C}_{2} \mathrm{O}_{5}^{2-}\right)$, but the slower kinetics are consistent with the lower temperature. On average, the pyrocarbonate is present about $f_{\mathrm{C}_{2} \mathrm{O}_{5}^{2-}}=19 \%$ of the time, which means that, even as a transient species, it impacts quantitatively the thermodynamics of the solvated $\mathrm{CO}_{2}$ (e.g. its solubility and its redox potential). From the fraction of time of presence of the pyrocarbonate $f_{\mathrm{C}_{2} \mathrm{O}_{5}^{2-}}$, we estimated the free en-

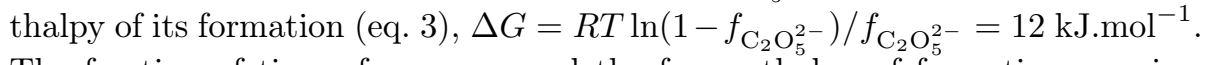
The fraction of time of presence and the free enthalpy of formation are similar as in $\mathrm{CaCO}_{3}$ at $1773 \mathrm{~K}: 0.24 \%$ and $16.8 \mathrm{~kJ} \mathrm{~mol}^{-1}$, respectively. We also estimated the enthalpy of formation by considering the difference of average potential energy in presence of pyrocarbonate and in presence of $\mathrm{CO}_{2}$, $\Delta H=\langle U\rangle_{\mathrm{C}_{2} \mathrm{O}_{5}^{2-}}-\langle U\rangle_{\mathrm{CO}_{2}}=45 \mathrm{~kJ} . \mathrm{mol}^{-1}$, where the bracket $\langle\cdot\rangle_{I}$ indicates an average over configurations where the species I is present. The reaction (3) is thus endothermic, meaning the fraction of pyrocarbonate will increase at higher temperature. The entropy of formation, $\Delta S=(\Delta H-\Delta G) / T=33 \mathrm{~J}_{\mathrm{mol}}^{-1}$, is positive, which indicates the formation of pyrocarbonate is entropically favoured. This latter observation seems counter-intuitive as the reaction 3 reduced the number of molecules from 2 to 1 , i.e. a decrease in the translational entropy. In section 3.2.1 and 3.2.2, we will analyse the solvation of $\mathrm{CO}_{2}$ and $\mathrm{C}_{2} \mathrm{O}_{5}^{2-}$ and show that the solvation structure of the latter is more disordered, which may explain the positive entropy of formation.

\subsection{Intramolecular and Intermolecular Structure}

We now explore the interactions between the solvated species and the molten carbonate, in particular to understand their differences in stability and reactivity. We consider the intramolecular structure (distances, angles and dihedral angles) as well as the intermolecular solvation structures.

\subsubsection{Carbon dioxide}

We first focus on the properties of $\mathrm{CO}_{2}$, the key molecule in the redox processes occurring within MCFC and MCEC. From the first-principles MD simulations of $\mathrm{CO}_{2}$ solvated in $\mathrm{LiKCO}_{3}$ and $\mathrm{CO}_{2}$ isolated, we extracted the geometrical properties that characterized the $\mathrm{CO}_{2}$ molecule: the $\mathrm{C}-\mathrm{O}$ distance and the $\widehat{\mathrm{OCO}}$ angle. Table 1 gathers the average value and the standard deviation obtained in both phases at $T=1000 \mathrm{~K}$. The average C-O distance and 


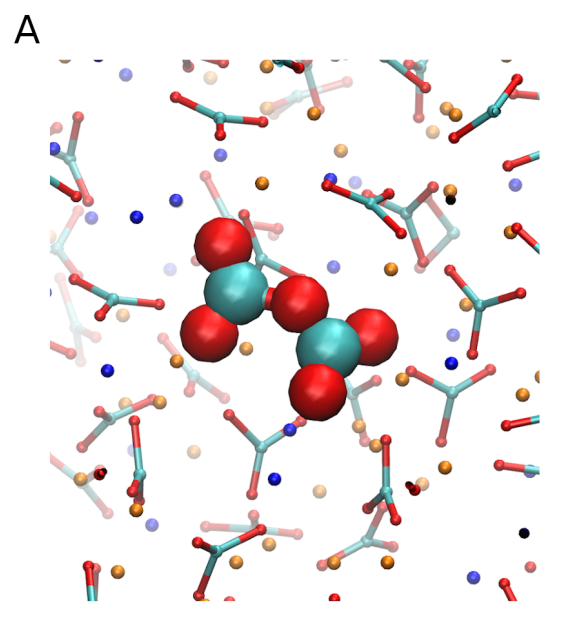

B

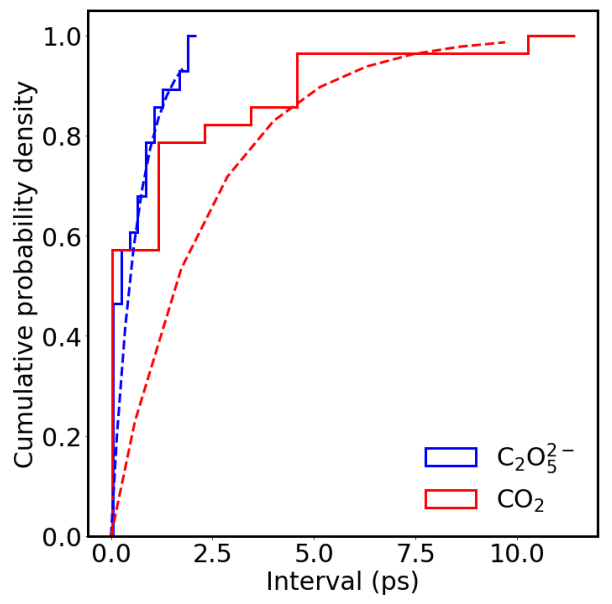

Figure 1: Formation/dissociation of pyrocarbonate $\mathrm{C}_{2} \mathrm{O}_{5}^{2-}$. (a) Snapshot of $\mathrm{C}_{2} \mathrm{O}_{5}^{2-}$ formed in the eutectic $\mathrm{LiKCO}_{3}$. Carbonate molecules in the solvent are represented by cyan/red sticks, $\mathrm{O}$ atoms by red spheres, $\mathrm{K}$ atoms in blue and $\mathrm{Li}$ atoms in orange. (b) Cumulative lifetime distribution of $\mathrm{CO}_{2}$ and of $\mathrm{C}_{2} \mathrm{O}_{5}^{2-}$ and exponential fit of these distributions (dashed lines).

Table 1: Geometry of the different molecules in the eutectic $\mathrm{LiKCO}_{3}$ and for an isolated species at $\mathrm{T}=1000 \mathrm{~K}$. Mean and standard deviation are obtained from the distribution of the geometrical properties (distance and angle) extracted from the MD simulations. The central atom of the $\mathrm{C}_{2} \mathrm{O}_{5}^{2-}$ is labelled $\mathrm{O}^{*}$.

\begin{tabular}{|c|c|c|c|c|c|}
\hline Molecule & $\begin{array}{c}\text { Geometrical } \\
\text { properties }\end{array}$ & \multicolumn{2}{|c|}{ in $\mathrm{LiKCO}_{3}$} & \multicolumn{2}{c|}{ isolated species } \\
Mean & $\begin{array}{c}\text { Standard } \\
\text { deviation }\end{array}$ & $\begin{array}{c}\text { Standard } \\
\text { deviation }\end{array}$ \\
\hline $\mathrm{CO}_{2}$ & $d_{\mathrm{CO}}(\AA)$ & 1.18 & 0.03 & 1.18 & 0.03 \\
& $\widehat{\mathrm{OCO}}\left(^{\circ}\right)$ & 167.0 & 7.9 & 170.3 & 5.8 \\
\hline $\mathrm{C}_{2} \mathrm{O}_{5}^{2-}$ & $d_{\mathrm{CO}}(\AA)$ & 1.26 & 0.05 & 1.27 & 0.04 \\
& $d_{\mathrm{CC}}(\AA)$ & 2.56 & 0.13 & 2.65 & 0.11 \\
& $d_{\mathrm{CO}}(\AA)$ & 1.49 & 0.11 & 1.51 & 0.09 \\
& $\widehat{\mathrm{OCO}}\left({ }^{\circ}\right)$ & 130.1 & 6.6 & 129.8 & 4.7 \\
& $\widehat{\mathrm{OCO}}\left(^{\circ}\right)$ & 114.5 & 6.3 & 114.7 & 5.7 \\
& $\widehat{\mathrm{CO}}{ }^{*} \mathrm{C}\left({ }^{\circ}\right)$ & 119.2 & 8.7 & 123.4 & 6.8 \\
\hline $\mathrm{C}_{2} \mathrm{O}_{4}^{2-}$ & $d_{\mathrm{CO}}(\AA)$ & 1.28 & 0.05 & 1.29 & 0.04 \\
& $d_{\mathrm{CC}}(\AA)$ & 1.57 & 0.08 & 1.65 & 0.09 \\
& $\widehat{\mathrm{OCO}}\left(^{\circ}\right)$ & 125.4 & 5.1 & 125.3 & 5.1 \\
& $\widehat{\mathrm{OCC}}\left(^{\circ}\right)$ & 116.8 & 6.0 & 117.1 & 5.9 \\
\hline $\mathrm{CO}$ & $d_{\mathrm{CO}}(\AA)$ & 1.16 & 0.06 & 1.15 & 0.02 \\
\hline
\end{tabular}



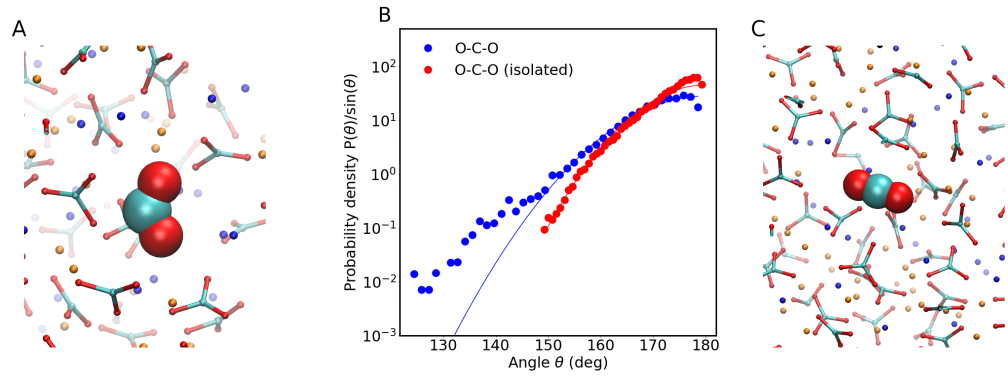

Figure 2: Intramolecular properties of $\mathrm{CO}_{2}$ molecule. (a,c) Snapshots of $\mathrm{CO}_{2}$ solvated in $\mathrm{LiKCO}_{3}$ illustrating (a) a bended configuration $\left(\widehat{\mathrm{OCO}}=124.4^{\circ}\right)$ and (c) a linear configuration $\left(\widehat{\mathrm{OCO}}=179.9^{\circ}\right)$. (b) Distribution of O-C-O angle of the $\mathrm{CO}_{2}$ molecule solvated in the eutectic $\mathrm{LiKCO}_{3}$ at $1000 \mathrm{~K}$ and isolated. For the solvated molecule, angles are measured during the time intervals of existence of $\mathrm{CO}_{2}$. The distribution is normalized by dividing by $\sin \theta$. Gaussian fits of the form $\exp \left(A\left(\theta-180^{\circ}\right)^{2}+B\right)$ are shown as blue and red solid lines for the solvated molecule and isolated molecule cases. Values of the fitted parameters: $\mathrm{A}=$ $-0.0045, \mathrm{~B}=3.33$ (solvated molecule) and $\mathrm{A}=-0.0067, \mathrm{~B}=3.81$ (isolated molecule).

standard deviation are identical in $\mathrm{LiKCO}_{3}$ and isolated $(1.18 \AA$ and $0.03 \AA$, respectively). If the average and standard deviation of the $\widehat{\mathrm{OCO}}$ angle are also similar for $\mathrm{CO}_{2}$ solvated in $\mathrm{LiKCO}_{3}$ and isolated, the full distribution (shown in Fig. 2(b)) are markedly different between the two phases. The distribution of $\mathrm{CO}_{2}$ solvated in $\mathrm{LiKCO}_{3}$ is broader than for an isolated $\mathrm{CO}_{2}$ molecule, with a long-tail $\left(\widehat{\mathrm{OCO}}<140^{\circ}\right)$ that displays an exponential-like decay, while the full distribution for the isolated molecule coincides almost with a Gaussian curve. Fig. 2(a) illustrates a bended configuration of $\mathrm{CO}_{2}$ solvated in $\mathrm{LiKCO}_{3}$ while Fig. 2(c) shows a perfectly linear configuration of $\mathrm{CO}_{2}$. If we had previously noticed a broader distribution of $\widehat{\mathrm{OCO}}$ in the case of a $\mathrm{CO}_{2}$ molecule solvated in $\mathrm{CaCO}_{3}$ at $T=1773 \mathrm{~K}$ compared to the isolated molecule distribution at the same temperature, the $\widehat{\mathrm{OCO}}$ distribution in $\mathrm{CaCO}_{3}$ coincides however with a Gaussian curve, even at small angles $\left(\widehat{\mathrm{OCO}}<140^{\circ}\right)$. In both $\mathrm{LiKCO}_{3}$ and $\mathrm{CaCO}_{3}$, these large $\widehat{\mathrm{OCO}}$ distributions indicate that the $\mathrm{CO}_{2}$ molecules can bend up to $120^{\circ}$, facilitating the formation of the pyrocarbonate. The larger distribution in $\mathrm{LiKCO}_{3}$ implies the $\mathrm{CO}_{2}$ bending is more likely in this molten carbonate rather than in $\mathrm{CaCO}_{3}$, but the difference of temperature between the two systems $\left(1000 \mathrm{~K}\right.$ in $\mathrm{LiKCO}_{3}$ and $1773 \mathrm{~K}$ in $\left.\mathrm{CaCO}_{3}\right)$ prevents us from discussing further the (small) difference of lifetime of $\mathrm{CO}_{2}$ (2.3 ps in $\mathrm{LiKCO}_{3}$ and $0.88 \mathrm{ps}$ in $\mathrm{CaCO}_{3}$ ).

To understand better the formation of the pyrocarbonate, we explored the solvation structure around $\mathrm{CO}_{2}$ and its specific interactions with the different ions of the melt. Fig. 3 displays the radial distribution function (RDF) between (a) the carbon atom $\left(\mathrm{C}_{\mathrm{CO}_{2}}\right)$ and (b) the oxygen atoms $\left(\mathrm{O}_{\mathrm{CO}_{2}}\right)$ and all the solvent atoms $(\mathrm{K}, \mathrm{Li}$ and $\mathrm{C}$ and $\mathrm{O}$ atoms of the carbonate, denoted respectively 
$\mathrm{C}_{\text {carb }}$ and $\left.\mathrm{O}_{\text {carb }}\right)$. The potassium cations show the strongest affinity with the $\mathrm{CO}_{2}$ molecule, with a clear intermolecular structure characterized by two peaks, at $4 \AA$ and $6.5 \AA$ for $\mathrm{C}_{\mathrm{CO}_{2}}$ and $3.5 \AA$ and $7 \AA$ for $\mathrm{O}_{\mathrm{CO}_{2}}$. The situation is notably different for the lithium cations, for which we observed no peaks in the RDF with $\mathrm{C}_{\mathrm{CO}_{2}}$ or $\mathrm{O}_{\mathrm{CO}_{2}}$, meaning that no specific interaction exists between $\mathrm{CO}_{2}$ and lithium. This absence of interaction may be explained by the competition with the strong lithium-carbonate interactions. The latter is revealed in the RDFs for $\mathrm{C}_{\text {carb }}-\mathrm{Li}$ and $\mathrm{O}_{\text {carb }}-\mathrm{Li}$ pairs shown in the Fig. 4 of Ref. [16]. The $\mathrm{O}_{\text {carb-Li }} \mathrm{RDF}$ displays in particular a very strong peak at $2.5 \AA$. The neutral $\mathrm{CO}_{2}$ molecule cannot interact strongly enough with $\mathrm{Li}^{+}$to counteract the $\mathrm{CO}_{3}^{2-}-\mathrm{Li}^{+}$interaction and $\mathrm{Li}$ does not form a solvation structure around $\mathrm{CO}_{2}$.

The RDFs give only access to isotropic information and therefore neglect the particular orientation of the $\mathrm{CO}_{2}$ with respect to the carbonate, potassium and lithium ions. To better highlight the three-dimensional solvation structure of $\mathrm{CO}_{2}$, we built two-dimensional histograms of the probability of the presence of the solvent atoms $\left(\mathrm{C}_{\mathrm{carb}}, \mathrm{O}_{\text {carb }}, \mathrm{Li}\right.$ and $\left.\mathrm{K}\right)$ around $\mathrm{CO}_{2}$ in a cylindrical $\rho-\zeta$ coordinate system, where $\zeta$ is the projection of an atom position along

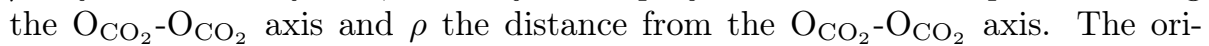
gin of the the cylindrical coordinate system is chosen to be the mid-point of the $\mathrm{O}_{\mathrm{CO}_{2}}-\mathrm{O}_{\mathrm{CO}_{2}}$ vector, i.e. close to the average position of $\mathrm{C}_{\mathrm{CO}_{2}}$. Fig. 4(a-d) shows these two-dimensional histograms for $\mathrm{C}_{\mathrm{carb}}, \mathrm{O}_{\mathrm{carb}}$, $\mathrm{Li}$ and $\mathrm{K}$ atoms, respectively.

Fig. 4(a-b) reveals a preferential orientation of $\mathrm{CO}_{3}^{2-}$ with respect to $\mathrm{CO}_{2}$. The highest probability of presence is observed in the region $3<\rho<4 \AA$ and $-1<\zeta<1 \AA$ for $\mathrm{C}_{\text {carb }}$ and in the region $2.5<\rho<3.5 \AA$ and $-0.5<\zeta<$ $0.5 \AA$ for $\mathrm{O}_{\text {carb. }}$. The solvation of the $\mathrm{CO}_{2}$ molecule by the carbonate anion is thus characterized by a preferential structure where one $\mathrm{O}$ of the solvating carbonate is in the plane of symmetry orthogonal to $\mathrm{CO}_{2}$. Such a preferential orientation was previously observed for $\mathrm{CO}_{2}$ solvated in the molten $\mathrm{CaCO}_{3}$ and participates to the formation of the pyrocarbonate. The solvation structure of $\mathrm{K}^{+}$around $\mathrm{CO}_{2}$ is also anisotropic, as shown in Fig. 4(d). The presence of $\mathrm{K}^{+}$is the highest within two regions, which are symmetrical with respect to the $\zeta=0$ axis, which have the shape of an arc of circle with center $\mathrm{C}_{\mathrm{CO}_{2}}$ and a radius of $4 \AA$ (that corresponds to the first peak in the RDF between $\mathrm{K}$ and $\mathrm{C}_{\mathrm{CO}_{2}}$ ) and which extend between the angles $46^{\circ}$ and $65^{\circ}$ with respect to the $\zeta=0$ axis (maximum around $56^{\circ}$ ). The potassium cation positions preferentially between the carbon and the oxygen atoms and close to the $\mathrm{CO}_{2}$ molecule. The twodimensional histogram has thus permitted to analyse in details the first peak of the $\mathrm{K}-\mathrm{C}_{\mathrm{CO}_{2}}$ RDF. Such a double-arc structure in-between $\mathrm{C}$ and $\mathrm{O}$ atoms was also observed in the case of the probability of presence of $\mathrm{Ca}$ atoms around $\mathrm{CO}_{2}$ in $\mathrm{CaCO}_{3}$, which indicates that $\mathrm{K}^{+}$and $\mathrm{Ca}^{2+}$ play similar role in the solvation of $\mathrm{CO}_{2}$. On the other hand, the lithium solvation structure (displayed in Fig. 4(c)) does not show any preferred positions for lithium around $\mathrm{CO}_{2}$, which confirms the previous analysis of the $\mathrm{Li}-\mathrm{C}_{\mathrm{CO}_{2}} \mathrm{RDF}$ and corroborates the absence of specific $\mathrm{Li}-\mathrm{CO}_{2}$ interaction, probably due to the strong $\mathrm{Li}^{+}-\mathrm{CO}_{3}^{2-}$ 

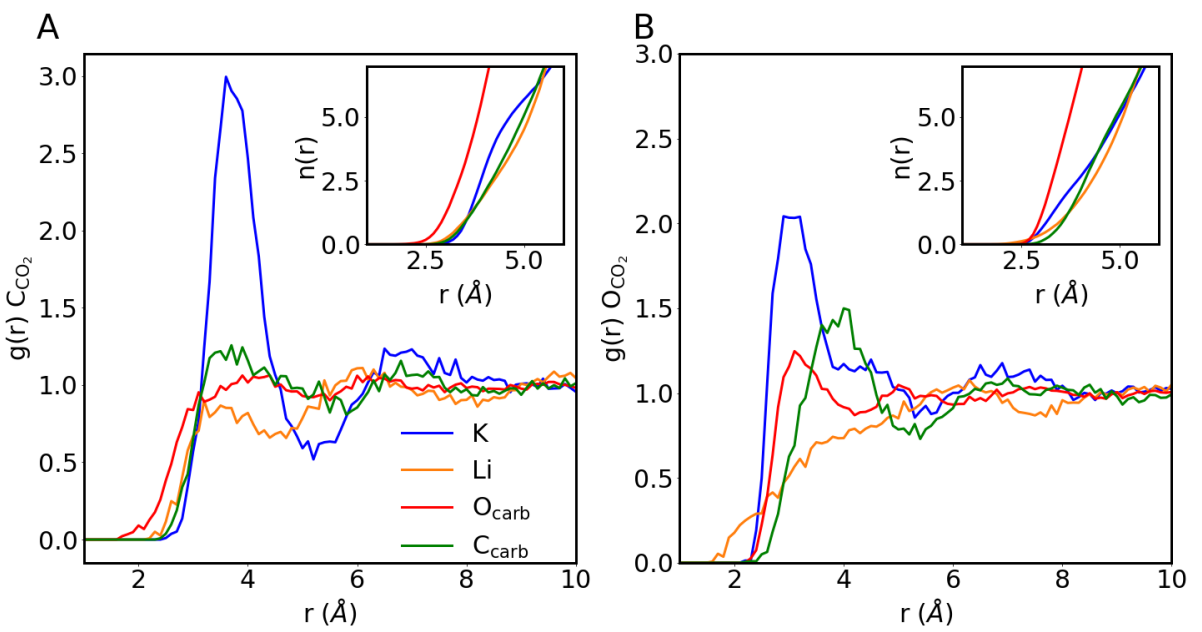

Figure 3: Radial distribution function (RDF) around the (a) oxygen atom of $\mathrm{CO}_{2}$ molecule $\mathrm{O}_{\mathrm{CO}_{2}}$ and (b) carbon atom of $\mathrm{CO}_{2}$ molecule $\mathrm{C}_{\mathrm{CO}_{2}}$. Intermolecular distances are measured during the time of existence of $\mathrm{CO}_{2}$ as a molecular species. Insets: coordination number $n(r)$ obtained from the integration of the radial distribution functions. The same color code applies for figures (a) and (b).

interaction. The observation of the different solvation structures formed by $\mathrm{Li}$ and $\mathrm{K}$ around $\mathrm{CO}_{2}$ is a major step to understand the role of the molten carbonate composition in the solubility or diffusivity of $\mathrm{CO}_{2}$.

\subsubsection{Pyrocarbonate anion, $\mathrm{C}_{2} \mathrm{O}_{5}^{2-}$}

We will now consider the structure and the solvation of the unusual pyrocarbonate cation formed by reaction between the solvated $\mathrm{CO}_{2}$ molecule and a carbonate $\mathrm{CO}_{3}^{2-}$ of the solvent. We first calculated the average and standard deviation of the intramolecular distances, both for a pyrocarbonate solvated within the molten carbonate and isolated. The central oxygen atom of $\mathrm{C}_{2} \mathrm{O}_{5}^{2-}$ will be labelled $\mathrm{O}^{*}$ while the four external oxygens and the two carbons will be labelled $\mathrm{O}$ and $\mathrm{C}$. Table 1 gathers these distances, that follow on average the trend $\left\langle d_{\mathrm{CO}}\right\rangle\left\langle\left\langle d_{\mathrm{CO}^{*}}\right\rangle\left\langle\left\langle d_{\mathrm{CC}}\right\rangle\right.\right.$ and whose standard deviations due to thermal fluctuations are relatively low (between $4 \%$ and $7 \%$ ). The distances $d_{\mathrm{CO}}$ and $d_{\mathrm{CO}^{*}}$ are almost identical between the solvated pyrocarbonate and the isolated pyrocarbonate (with difference in average value or standard deviation < $0.02 \AA$ ), while $\left\langle d_{\mathrm{CO}}\right\rangle$ is slightly longer for the isolated molecule, with an increase of $0.09 \AA$ compared to the solvated anion. The average intramolecular distances of the pyrocarbonate in $\mathrm{LiKCO}_{3}$ are also similar to the one in $\mathrm{CaCO}_{3}$, whose average value are $1.26 \AA, 1.43 \AA$ and $2.53 \AA$ for $d_{\mathrm{CO}}, d_{\mathrm{CO}^{*}}$ and $d_{\mathrm{CC}}$, respectively. Table 1 also displays the average and standard deviation of the three intramolecular angles of the pyrocarbonate. Like for the distances, the thermal fluctuations are of the order of $5 \%$ to $7 \%$, the average values are equivalent between the solvated and the isolated molecule (with the maximum difference 


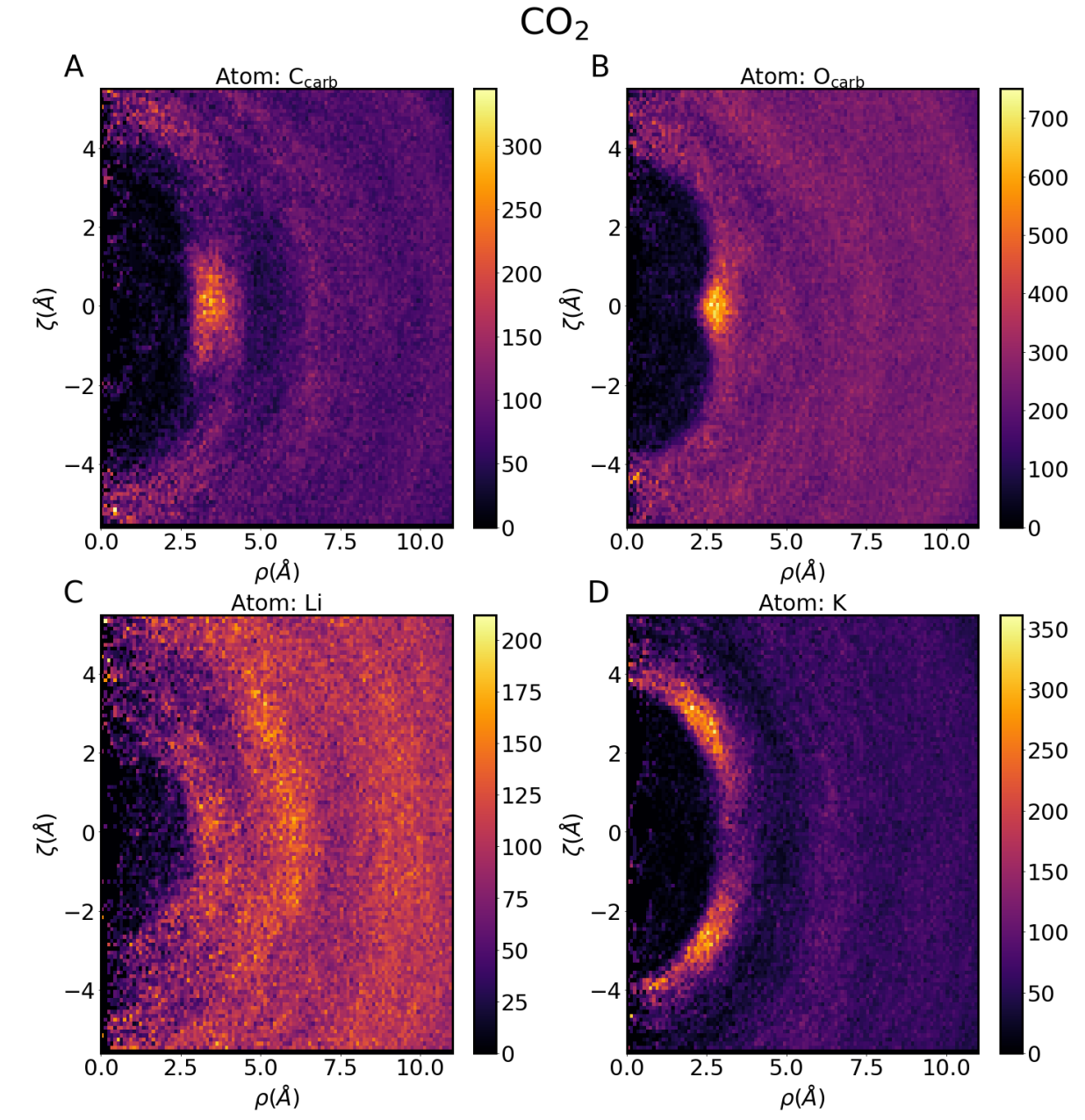

Figure 4: Solvation structure around the $\mathrm{CO}_{2}$ molecule. Two dimensional colour charts representing the probability of the presence of the following atoms around $\mathrm{CO}_{2}: \mathrm{C}_{\text {carb }}$ atom (a); $\mathrm{O}_{\text {carb }}$ atom (b): $\mathrm{Li}$ atom (c) and $\mathrm{K}$ atom (d). $\mathrm{CO}_{2}$ is oriented with its $\mathrm{O}_{\mathrm{CO}_{2}}-\mathrm{O}_{\mathrm{CO}_{2}}$ axis along the $\hat{\zeta}$ direction, where $\zeta=0$ is the mid-point of the O-O distance. $\zeta$ is thus the projection of an atom position along the $\mathrm{O}_{\mathrm{CO}_{2}}-\mathrm{O}_{\mathrm{CO}_{2}}$ axis, and $\rho$ its distance from the $\mathrm{O}_{\mathrm{CO}_{2}}-\mathrm{O}_{\mathrm{CO}_{2}}$ axis. 
for $\widehat{\mathrm{CO}^{*} \mathrm{C}}$ at $\left.4.2^{\circ}\right)$. They are also very close between pyrocarbonate ion solvated in $\mathrm{LiKCO}_{3}$ and ion solvated in $\mathrm{CaCO}_{3}$ (with the maximum difference for $\widehat{\mathrm{CO}^{*} \mathrm{C}}$ at $4.0^{\circ}$ ). Finally, we conclude the analysis of the geometry of $\mathrm{C}_{2} \mathrm{O}_{5}^{2-}$ by looking at the dihedral angle $\mathrm{OCO}^{*} \mathrm{C}$. Fig. 5 displays the distributions of $\mathrm{OCO}^{*} \mathrm{C}$ for the solvated and isolated pyrocarbonate. Both distributions peak around $0^{\circ}$ and $180^{\circ}$ which indicates the pyrocarbonate forms preferentially a planar structure. The probability to observe other angles is however far from negligible: the smallest probability is found for dihedral angles of $\pm 90^{\circ}$ and is only half of the highest probability (planar structure). $\mathrm{C}_{2} \mathrm{O}_{5}^{2-}$ is therefore flexible and it alternates planar and twisted structures.

To understand the formation and relative stability of this transient species, we analyse here its solvation structure. We start with the RDF (shown in Fig. 6(a-c) ), between the three types atoms of $\mathrm{C}_{2} \mathrm{O}_{5}^{2-}\left(\mathrm{C}_{\text {pyro }}, \mathrm{O}_{\text {pyro }}\right.$ and $\mathrm{O}_{\text {pyro }}^{*}$, respectively) and the four solvent atoms $\left(\mathrm{C}_{\text {carb }}, \mathrm{O}_{\text {carb }}, \mathrm{Li}\right.$ and $\left.\mathrm{K}\right)$. The RDFs reveal a different structure of solvation compared to the $\mathrm{CO}_{2}$ molecule: the closest peak (i.e. intramolecular distance) occur now with $\mathrm{Li}$ for all atoms in pyrocarbonate, with distances of $3 \AA$ and $2 \AA$ for $\mathrm{C}_{\text {pyro }}$ and $\mathrm{O}_{\text {pyro }}$ respectively. But except for these peaks, the lithium solvation does not present a medium-range structure (RDF close to 1 after $5 \AA$ ). The RDFs $\mathrm{K}-\mathrm{C}_{\text {pyro }}$ and $\mathrm{K}-\mathrm{O}_{\text {pyro }}$ are characterized by a double-peak structure, more pronounced for $\mathrm{C}_{\text {pyro }}$, a behaviour similar to the one observed around $\mathrm{CO}_{2}$. The RDFs between the carbonate atoms and $\mathrm{C}_{\text {pyro }}$ and $\mathrm{O}_{\text {pyro }}$ displays almost no solvation-induced structuration, with a small peak (RDF close to 1.3 ) between $\mathrm{C}_{\text {carb }}$ and $\mathrm{C}_{\text {pyro }}$ and $\mathrm{O}_{\text {pyro }}$ at $4 \AA$ and $6 \AA$ respectively, while no peaks occur for $\mathrm{C}_{\text {carb }}$. We conclude the discussion of the RDFs by noting that $\mathrm{O}_{\text {pyro }}^{*}$ is embedded with the pyrocarbonate molecule and less reachable: its RDFs with solvent atoms (see Fig. 6(c)) does not present any marked solvation structure (except a broad peak for potassium).

As explained in the case of $\mathrm{CO}_{2}$, the RDFs only provide isotropic information and we therefore calculated the two-dimensional cylindrical-based histograms to characterize the solvation structure and elucidate the peaks observed in the RDFs with respect to Li and K. Fig. 6(d-e) displays the cylindrical-coordinate density of probability of presence of solvent atoms surrounding the pyrocarbonate. $\zeta$ is now the projection along the $\mathrm{C}_{\text {pyro }}-\mathrm{C}_{\text {pyro }}$ axis, $\rho$ the distance with this axis and the origin is the midpoint between $\mathrm{C}_{\text {pyro }}$ atoms. To account for the dissymmetry that might be induced by the formation of pyorcarbonate from the reaction between $\mathrm{CO}_{2}$ and $\mathrm{CO}_{3}^{2-}$, we always placed the $\mathrm{C}$ from the former $\mathrm{CO}_{2}$ in the region $\zeta<0$. Fig. 6(c) shows that the lithium atoms surround almost homogeneously the pyrocarbonate, which means the peak in RDF between lithium and pyrocarbonate does not split clearly into different preferential positions. We note nevertheless a slightly higher density of probability in the arc of circle $\zeta \geq 0, \rho=3 \AA$ (and in particular in the place perpendicular to the pyrocarbonate, $\zeta=0$ ) which reveals that the lithium cation is closer to the former $\mathrm{CO}_{3}^{2-}$ than with the former $\mathrm{CO}_{2}$. The same analysis holds for the 


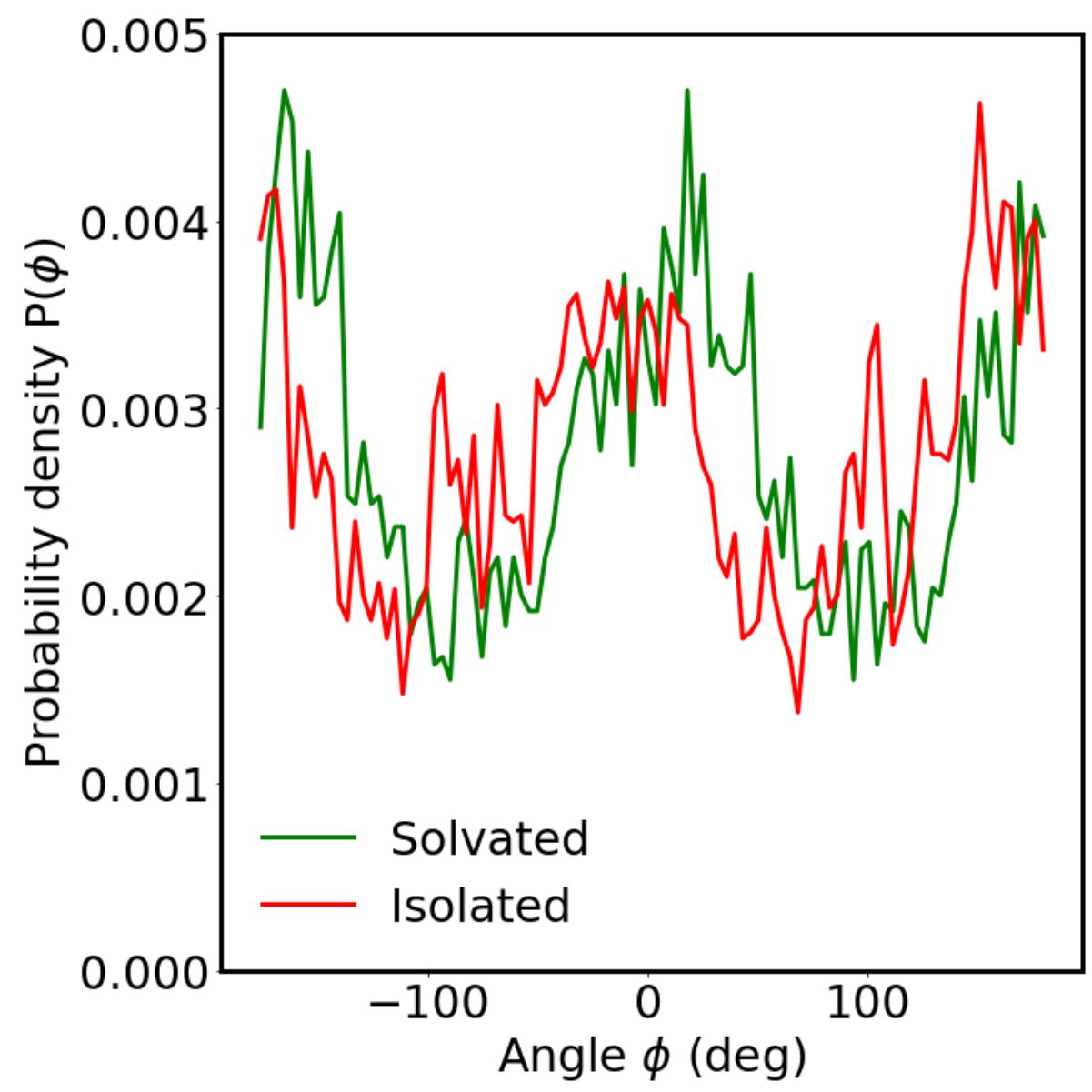

Figure 5: Distribution of O-C-O*-C dihedral angle of pyrocarbonate $\mathrm{C}_{2} \mathrm{O}_{5}^{2-}$ solvated in the eutectic $\mathrm{LiKCO}_{3}$ at $1000 \mathrm{~K}$ and isolated. For the solvated molecule, the dihedral angle is measured during the time intervals of existence of $\mathrm{C}_{2} \mathrm{O}_{5}^{2-}$. 
probability of presence of $\mathrm{K}^{+}$(shown in Fig. 6(d) which also surround homogeneously the pyrocarbonate but with a higher probability of presence both in the perpendicular plane but also in the $\mathrm{C}_{\mathrm{pyro}}-\mathrm{C}_{\text {pyro }}$ axis $(\rho=0 \AA, \zeta= \pm 4 \AA)$. We note that such homogeneous surrounding was also observed for the presence of calcium atoms around the pyrocarbonate formed in $\mathrm{CaCO}_{3}$, which again underlines the similar role played by $\mathrm{K}^{+}$and $\mathrm{Ca}^{2+}$ in the solvation of $\mathrm{CO}_{2}$ and $\mathrm{C}_{2} \mathrm{O}_{5}^{2-}$.

The cylindrical-coordinate density of probability reveals the key difference of the solvation structure around $\mathrm{CO}_{2}$ and around $\mathrm{C}_{2} \mathrm{O}_{5}^{2-}$ : (i) $\mathrm{Li}^{+}$rarely approach close to $\mathrm{CO}_{2}$ while it solvates $\mathrm{C}_{2} \mathrm{O}_{5}^{2-}$ homogeneously at $3 \AA$, and (ii) $\mathrm{K}^{+}$solvates $\mathrm{CO}_{2}$ anisotropically while it surrounds $\mathrm{C}_{2} \mathrm{O}_{5}^{2-}$ homogeneously. The difference of solvation of $\mathrm{Li}^{+}$may be related to the difference of charges of these molecules $\left(q_{\mathrm{CO}_{2}}=0, q_{\text {pyro }}=-2\right), \mathrm{C}_{2} \mathrm{O}_{5}^{2-}$ can compete with $\mathrm{CO}_{3}^{2-}$ to interact with the lithium cation, leading to that stronger solvation than between $\mathrm{CO}_{2}$ and $\mathrm{Li}$. The slight anisotropy of solvation of $\mathrm{Li}^{+}$around $\mathrm{C}_{2} \mathrm{O}_{5}^{2-}$ is another signature of stronger solvation of $\mathrm{Li}^{+}$with the former $\mathrm{CO}_{3}^{2-}$ than to the former $\mathrm{CO}_{2}$. It indicates that the solvation structure around $\mathrm{C}_{2} \mathrm{O}_{5}^{2-}$ may not reach a fully equilibrated configuration (which would have been symmetrical) during the short lifetime of existence of $\mathrm{C}_{2} \mathrm{O}_{5}^{2-}$. The potassium plays a role in the solvation of both $\mathrm{CO}_{2}$ and $\mathrm{C}_{2} \mathrm{O}_{5}^{2-}$, but it displays a more disordered structure around $\mathrm{C}_{2} \mathrm{O}_{5}^{2-}$. This result may contribute to the positive sign of the entropy of formation discussed in section 3.1. When the pyrocarbonate anion is formed, the anisotropic solvation structure of $\mathrm{K}^{+}$around $\mathrm{CO}_{2}$ disappears, leading to a increase of entropy.

\subsubsection{Oxalate anion, $\mathrm{C}_{2} \mathrm{O}_{4}^{2-}$}

Besides $\mathrm{CO}_{2}$ and pyrocarbonate, the oxalate anion $\mathrm{C}_{2} \mathrm{O}_{4}^{2-}$ may also play a role in the electrochemical properties of MCFC and MCEC. The formation of this species can occur via the reaction between $\mathrm{CO}$ and $\mathrm{CO}_{3}^{2-}$ (eq. 4), though we did not directly observe this reaction in the system containing a $\mathrm{CO}$ molecule or the inverse reaction in the system containing $\mathrm{C}_{2} \mathrm{O}_{4}^{2-}$ (see the discussion on stability in section 3.1). From the 60 ps MD trajectory containing the stable $\mathrm{C}_{2} \mathrm{O}_{4}^{2-}$ solvated in $\mathrm{LiKCO}_{3}$, we extracted the intramolecular and solvation structure, in particular to understand its relative stability in comparison with the pyrocarbonate.

The oxalate intramolecular geometry is characterized by two distances $\left(d_{\mathrm{CC}}\right.$ and $\left.d_{\mathrm{CO}}\right)$, two angles $(\widehat{\mathrm{OCC}}$ and $\widehat{\mathrm{OCO}})$ whose average values and standard deviations in both molten carbonate and vacuum (i.e. for the isolated molecule) are presented in Table 1 . The shortest distance is $d_{\mathrm{CO}}$, with an average value $(1.28 \AA)$ close to that of pyrocarbonate $(1.26 \AA)$ but $8 \%$ longer than in $\mathrm{CO}_{2}$ $(1.18 \AA)$. Similarly to what we observed for $\mathrm{CO}_{2}$ and the pyrocarbonate anion, the thermal fluctuations for the distances and the angles are small (about $5 \%$ ) and solvated oxalate and isolated oxalate ions have almost identical structure (only the CC distance is $5 \%$ higher for the isolated molecule). Finally, 


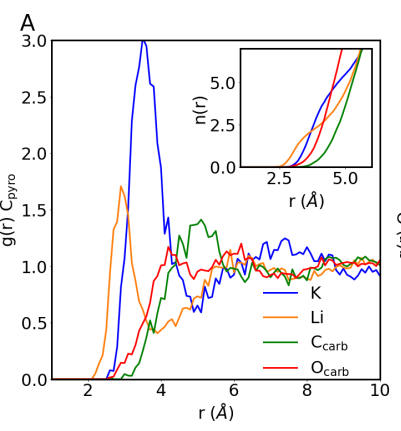

D Atom: Li

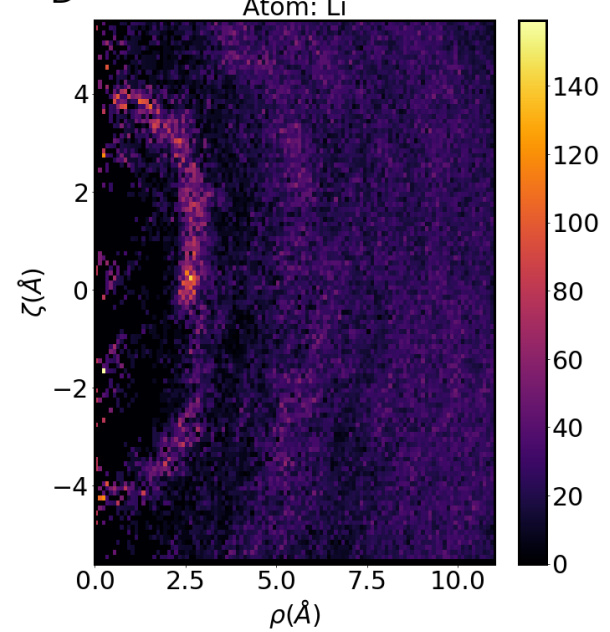

$\mathrm{C}_{2} \mathrm{O}_{5}^{2-}$
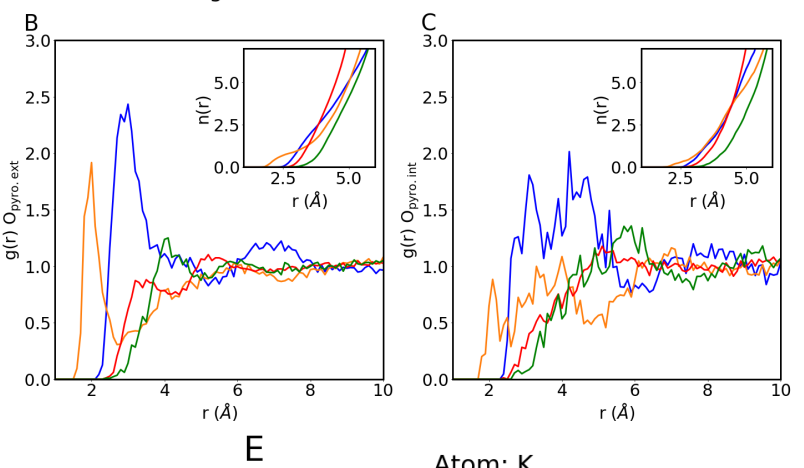

E

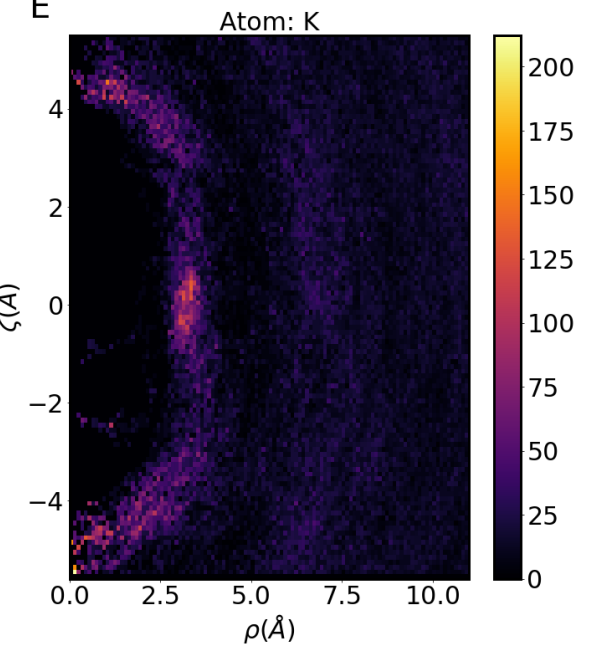

Figure 6: Solvation structure around the pyrocarbonate anion $\mathrm{C}_{2} \mathrm{O}_{5}^{2-}$. Upper panel: radial distribution function (RDF) for (a) carbon atom (b) external oxygen atoms and (c) internal oxygen atom of $\mathrm{C}_{2} \mathrm{O}_{5}^{2-}$. Insets: coordination number $n(r)$ obtained from the integration of the radial distribution functions. The same color code applies for figures (a), (b) and (c). Lower panel: two dimensional colour charts representing the probability of the presence of the following atoms around $\mathrm{C}_{2} \mathrm{O}_{5}^{2-}: \mathrm{Li}$ atom (d) and $\mathrm{K}$ atom (e). $\mathrm{C}_{2} \mathrm{O}_{5}^{2-}$ is oriented with its $\mathrm{C}_{\text {pyro }}-\mathrm{C}_{\text {pyro }}$ axis along the $\hat{\zeta}$ direction, where $\zeta=0$ is the mid-point of the $\mathrm{C}_{\text {pyro- }}-\mathrm{C}_{\text {pyro }}$ distance. $\zeta$ is thus the projection of an atom position along the $\mathrm{C}_{\mathrm{pyro}}-\mathrm{C}_{\mathrm{pyro}}$ axis, and $\rho$ its distance from the $\mathrm{C}_{\mathrm{pyro}}-\mathrm{C}_{\mathrm{pyro}}$ axis. The $\mathrm{C}$ of the former $\mathrm{CO}_{2}$ molecule is always placed in the negative $\zeta$ portion of the plots. 

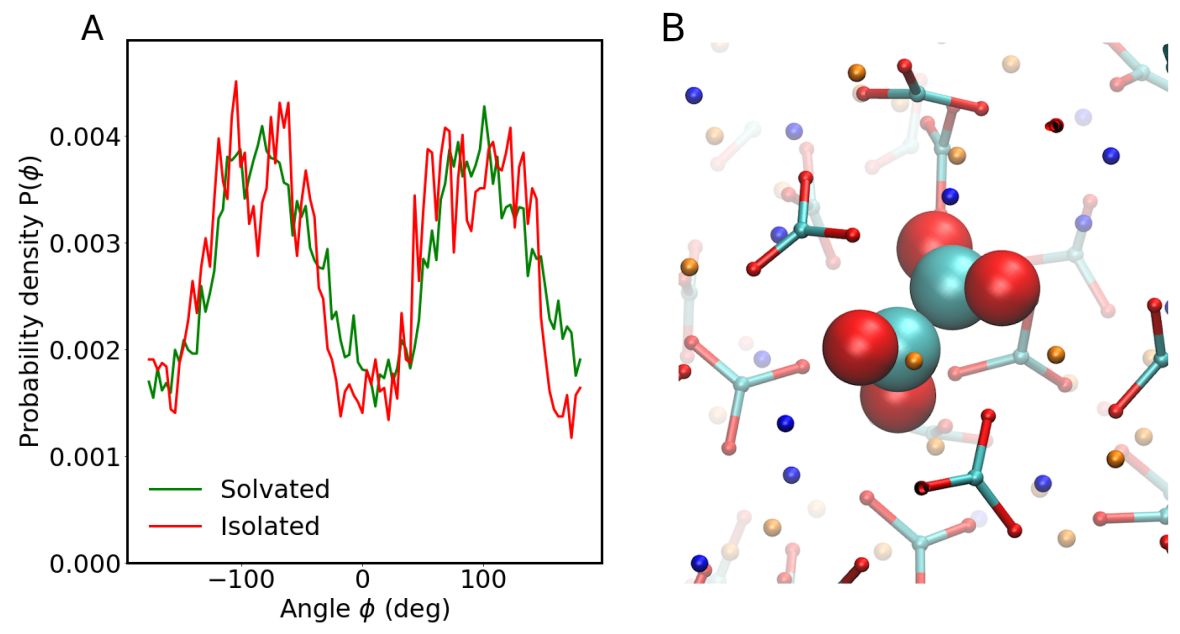

Figure 7: (a) Distribution of O-C-C-O dihedral angle of oxalate $\mathrm{C}_{2} \mathrm{O}_{4}^{2-}$ solvated in the eutectic LiKCO3 at $1000 \mathrm{~K}$ and isolated. (b) Snapshot of $\mathrm{C}_{2} \mathrm{O}_{4}^{2-}$ in the eutectic $\mathrm{LiKCO}_{3}$. Carbonate molecules in the solvent are represented by cyan/red sticks, $\mathrm{O}$ atoms by red spheres, $\mathrm{K}$ atoms in blue and $\mathrm{Li}$ atoms in orange.

Fig. 7(a) shows the distribution of the dihedral angle OCCO for both the solvated molecule and the isolated one. The maxima of distribution are situated at $\pm 100^{\circ}$, indicating the oxalate is preferentially twisted (as illustrated in Fig. 7(b)). Similarly to what was observed for pyrocarbonate, the distribution of dihedral angles is widely spread, the minimum is found at $0^{\circ}$, with a probability only half of the maximal value. Like the pyrocarbonate ion, the oxalate anion is flexible and alternates twisted and planar structures when solvated in molten carbonate.

The solvation structure of the oxalate is characterized by the RDF (Fig.8(ab)) and the cylindrical density of probability (Fig. 8(c-d)). The analysis of RDFs between the atoms of the oxalate $\left(\mathrm{O}_{\text {oxa }}\right.$ and $\left.\mathrm{C}_{\text {oxa }}\right)$ and the solvent atoms reveal some similarity with the solvation structure of pyrocarbonate, both being anionic species: (i) the RDFs with lithium peak closer than the RDFs with potassium, with a larger $\mathrm{Li}-\mathrm{O}_{\text {oxa }} \mathrm{RDF}$ peak than $\mathrm{K}^{-\mathrm{C}_{\text {oxa }}}$, while $\mathrm{Li}-\mathrm{C}_{\text {oxa }} \mathrm{RDF}$ peak is smaller than $\mathrm{K}^{-\mathrm{C}_{\text {oxa }}} \mathrm{RDF}$ peak; (ii) the RDF K-C $\mathrm{C}_{\text {oxa }}$ exhibits a two-peak structure; (iii) the $\mathrm{RDFs}$ with $\mathrm{C}_{\text {carb }}$ and $\mathrm{O}_{\text {carb }}$ display only a very slight structuration, though the $\mathrm{RDF} \mathrm{C}_{\text {carb }}-\mathrm{C}_{\text {oxa }}$ presents two distinct peaks at $5 \AA$ and $9 \AA$.

Likewise, the cylindrical densities of probability of presence of Li and $\mathrm{K}$ (Fig. 8(c-d)) show some resemblance with the one of pyrocarbonate. Here the cylindrical coordinates are defined with respect to the $\mathrm{C}_{\text {oxa }}-\mathrm{C}_{\text {oxa }}$ axis, with $\zeta$ the projection onto this axis, $\rho$ the distance to that axis and the origin the midpoint of the $\mathrm{C}_{\text {oxa }}-\mathrm{C}_{\text {oxa }}$ bond. $\mathrm{Li}$ and $\mathrm{K}$ atoms surround homogeneously the 
oxalate, with a higher density for lithium along the $\mathrm{C}_{\text {oxa }}-\mathrm{C}_{\text {oxa }}$ and for potassium in the plane perpendicular to the $\mathrm{C}_{\text {oxa }}-\mathrm{C}_{\text {oxa }}$ axis $(\zeta=0 \AA)$ and along the $\mathrm{C}_{\text {oxa }}-\mathrm{C}_{\text {oxa }}$ axis. This solvation structure, close to that of $\mathrm{C}_{2} \mathrm{O}_{5}^{2-}$, indicates the existence of different solvation patterns between charged species (pyrocarbonate, oxalate) and neutral species $\left(\mathrm{CO}_{2}\right)$. The only minor difference between $\mathrm{C}_{2} \mathrm{O}_{4}^{2-}$ and $\mathrm{C}_{2} \mathrm{O}_{5}^{2-}$ relates to the lithium solvation structure which displays a slight asymmetry around $\mathrm{C}_{2} \mathrm{O}_{5}^{2-}$ but a perfect symmetry around $\mathrm{C}_{2} \mathrm{O}_{4}^{2-}$. As discussed in section 3.2.2, this asymmetry originates from the reacting species forming $\mathrm{C}_{2} \mathrm{O}_{5}^{2-}$. We will confirm the differential solvation patterns between charge and neutral species by looking now into the solvated $\mathrm{CO}$ molecules and the oxygen anion $\mathrm{O}^{2-}$.

\subsubsection{Carbon monoxide}

The production of carbon monoxide $\mathrm{CO}$ is one of the main objectives of molten carbonate electrolyser cells (MCEC) and we therefore present here the solvation properties of $\mathrm{CO}$ in the eutectic $\mathrm{LiKCO}_{3}$. In particular, the stability of $\mathrm{CO}$ discussed in section 3.1 will be analysed by comparing the solvation structures of $\mathrm{CO}$ and $\mathrm{CO}_{2}$. The dynamical properties, and in particular the diffusion, will be discussed in section 3.3.

From the 41 ps first-principles MD simulation, we measure the average C-O distance and standard deviation in both the molten carbonate and in vacuum (i.e. for the isolated molecule). The average $\mathrm{C}-\mathrm{O}$ distance is similar in molten carbonate and for the isolated molecule and is the smallest C-O intramolecular distance among the different solvated molecules we investigated (it is $0.02,0.10$ and $0.12 \AA$ smaller than $\mathrm{C}-\mathrm{O}$ distance in $\mathrm{CO}_{2}$, pyrocarbonate and oxalate, respectively), as expected due to its triple-bond nature. The thermal fluctuations are of the order of $5 \%$ in the molten carbonate and $3 \%$ for the isolated molecule.

More interestingly, the solvation around $\mathrm{CO}$ is notable for its absence of marked structure. Fig. 9(a-b) shows the RDFs between the two atoms of CO (panel (a) for $\mathrm{O}_{\mathrm{CO}}$ and panel (b) for $\mathrm{C}_{\mathrm{CO}}$ ) and the different solvent atoms. These RDFs present some similarity with the ones around $\mathrm{CO}_{2}$. First, the highest peak is between potassium and $\mathrm{C}_{\mathrm{CO}}$ and panel $\mathrm{O}_{\mathrm{CO}}$ at $3.5 \AA$ and $4 \AA$, respectively, with a second smaller peak observed between $\mathrm{C}_{\mathrm{CO}}$ and $\mathrm{K}$ at $6.5 \AA$. The first $\mathrm{C}_{\mathrm{CO}}-\mathrm{K}$ RDF peak reaches however a value of 2 for $\mathrm{CO}$ and 3 for $\mathrm{CO}_{2}$, that indicates a weaker interaction in the case of CO. Secondly, the RDFs with Li reveal an absence of preferential CO-Li distance, similar to that was already noticed for $\mathrm{CO}_{2}$. Finally, the RDFs with the carbonate atoms show a slight solvation structure around $\mathrm{O}_{\mathrm{CO}}$ : the $\mathrm{RDF} \mathrm{O}_{\text {carb }}-\mathrm{O}_{\mathrm{CO}}$ peaks at $3.5 \AA$ (with a value of 1.4), while the $\mathrm{RDF} \mathrm{O}_{\mathrm{CO}}-\mathrm{C}_{\text {carb }}$ peaks at $4 \AA$ (with a value of 1.5). As no peaks are observed for $\mathrm{C}_{\mathrm{CO}}$ in Fig. 9(b), this shows that the carbonate anion surrounds preferentially the oxygen atom of $\mathrm{CO}$, with one oxygen of $\mathrm{CO}_{3}^{2-}$ pointing toward $\mathrm{O}_{\mathrm{CO}}$. This specific interaction is explained by the positive charge carried by the $\mathrm{O}$ atom of $\mathrm{CO}$ (while $\mathrm{C}$ carries the opposite negative 

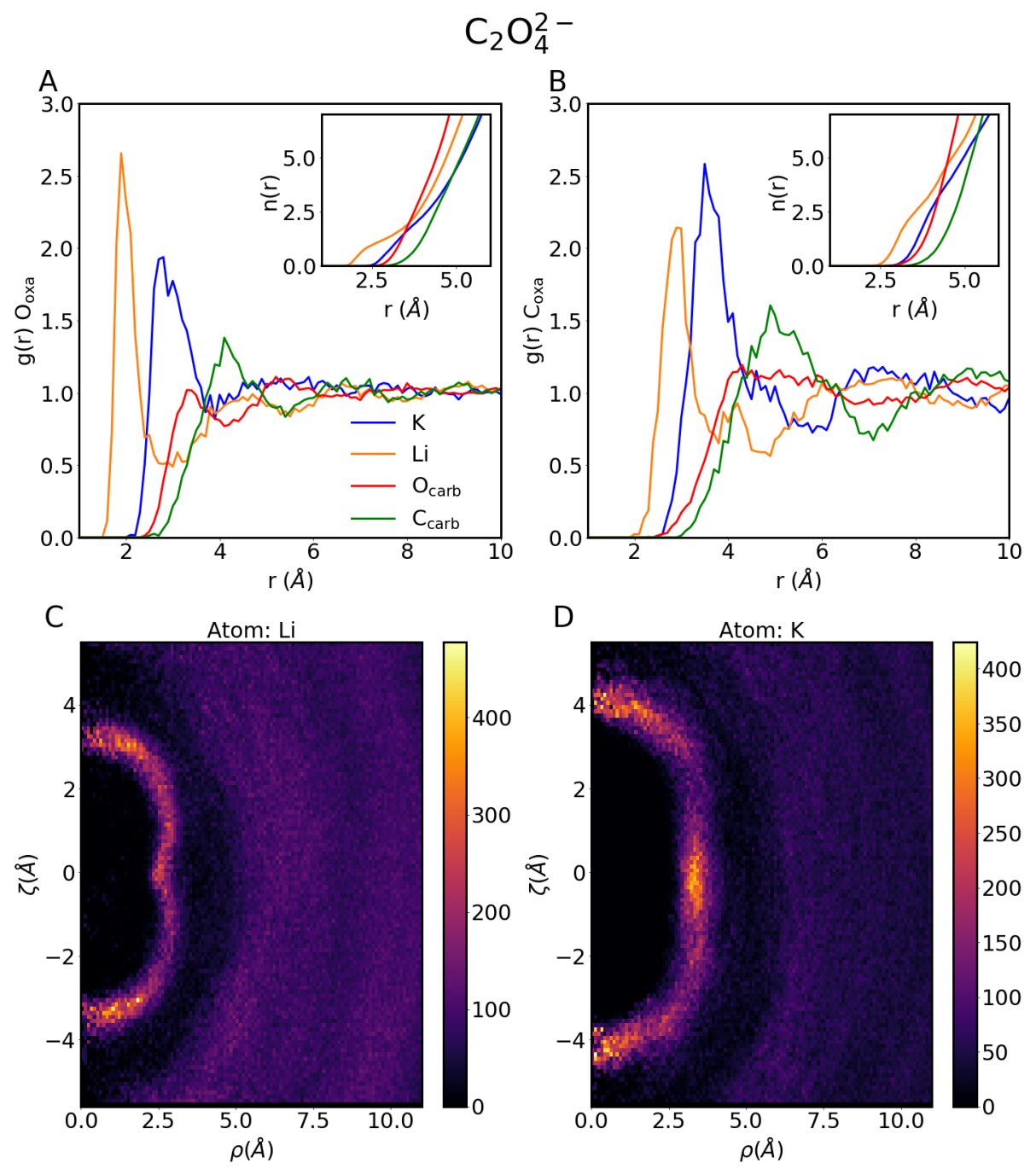

Figure 8: Solvation structure around the oxalate $\mathrm{C}_{2} \mathrm{O}_{4}^{2-}$ anion. Upper panel: radial distribution function (RDF) for (a) carbon atom of $\mathrm{C}_{2} \mathrm{O}_{4}^{2-}$ and (b) oxygen atom of $\mathrm{C}_{2} \mathrm{O}_{4}^{2-}$. Insets: coordination number $n(r)$ obtained from the integration of the radial distribution functions. The same color code applies for figures (a) and (b). Lower panel: two dimensional colour charts representing the probability of the presence of the following atoms around $\mathrm{C}_{2} \mathrm{O}_{4}^{2-}$ : Li atom (c) and $\mathrm{K}$ atom (d). $\mathrm{C}_{2} \mathrm{O}_{4}^{2-}$ is oriented with its $\mathrm{C}_{\text {oxa }}-\mathrm{C}_{\text {oxa }}$ axis along the $\hat{\zeta}$ direction, where $\zeta=0$ is the mid-point of the $\mathrm{C}_{\text {oxa }}-\mathrm{C}_{\text {oxa }}$ distance. $\zeta$ is thus the projection of an atom position along the $\mathrm{C}_{\text {oxa }}-\mathrm{C}_{\text {oxa }}$ axis, and $\rho$ its distance from the $\mathrm{C}_{\text {oxa }}-\mathrm{C}_{\text {oxa }}$ axis. 
charge).

This particular dipole of $\mathrm{CO}$ also impacts the cylindrical-coordinate density of probability for $\mathrm{Li}$ and $\mathrm{K}$ displayed in Fig. 9(c(d). Here the $\zeta$ coordinate is the projection onto the $\mathrm{C}_{\mathrm{CO}}-\mathrm{O}_{\mathrm{CO}}$ axis, $\rho$ is the distance to that axis, and the origin of the referential is the midpoint of the $\mathrm{C}_{\mathrm{CO}}-\mathrm{O}_{\mathrm{CO}}$ vector. The oxygen $\mathrm{O}_{\mathrm{CO}}$ is placed in the $\zeta<0$ portion of the plots. As seen in the RDF, the probability of presence of $\mathrm{Li}$ is more diffuse than the one of $\mathrm{K}$, but both $\mathrm{Li}$ and $\mathrm{K}$ show their highest probability of presence in the vicinity of $\mathrm{C}_{\mathrm{CO}}$, along the $\mathrm{C}_{\mathrm{CO}}-\mathrm{O}_{\mathrm{CO}}$ axis $(\rho=0 \AA, \zeta=3 \AA)$, i.e. the cations of the molten carbonate position preferentially close to the negatively charged $\mathrm{C}_{\mathrm{CO}}$.

Overall, $\mathrm{CO}$ presents a similar solvation pattern to $\mathrm{CO}_{2}$ with a strong solvation with $\mathrm{K}^{+}$and an (almost) absence of solvation with $\mathrm{Li}^{+}$. The main differences are (i) the preferential position of $\mathrm{Li}^{+}$close to $\mathrm{C}_{\mathrm{CO}}$, which is explained by the negatively charged carbon that can (slightly) compete with the $\mathrm{Li}^{+}-\mathrm{CO}_{3}^{2-}$ interaction, (ii) the absence of anisotropic potassium solvation structure around $\mathrm{CO}$ and (iii) the absence of preferential solvation of carbonate around CO.

\subsubsection{Oxygen anion}

We conclude our analysis of solvated species in the molten carbonate $\mathrm{LiKCO}_{3}$ with the oxygen anion $\mathrm{O}^{2-}$. $\mathrm{O}^{2-}$ may be involved in the electrochemical processes at the interface between molten carbonate and electrodes in MCFC or MCEC. Moreover, in that liquid melt, it also plays the important role of being the strongest oxo-base, an analogue of $\mathrm{OH}^{-}$in water. For this mono-atomic species, the solvation structure is isotropic and thus simply characterized by the RDFs with the different solvent atoms, shown in Fig. 10(a). The $\mathrm{Li}^{+}-\mathrm{O}^{2-} \mathrm{RDF}$ displays the most notable feature, with a high peak at $2 \AA$ (RDF reaches here a value of 17 ) followed by a minimum (RDF close to 0 ) at $3 \AA$. This peak induces a plateau is the coordination number $n(r)$ between 2 and $3 \AA$ at $n(r)=4$, which means that $\mathrm{O}^{2-}$ forms a relatively stable solvation shell with four lithium atoms. Besides the $\mathrm{O}^{2-}-\mathrm{Li}^{+} \mathrm{RDF}$ peak, each RDF between $\mathrm{O}^{2-}$ and the other solvent atoms displays successively a much smaller peak (RDF is around 2) at $3,3.5$ and $4 \AA$ for $\mathrm{K}, \mathrm{O}_{\text {carb }}$ and $\mathrm{C}_{\text {carb }}$, respectively.

To prolong the RDFs analysis, we calculate the joint probability of presence of $\mathrm{Li}^{+}$and $\mathrm{K}^{+}$in the first solvation shell of $\mathrm{O}^{2-}\left(\mathrm{Li}^{+}\right.$and $\mathrm{K}^{+}$are included in the shell if their distance with $\mathrm{O}^{2-}$ is below the first minimum in the respective RDFs, i.e. $3.1 \AA$ and $3.6 \AA$ respectively). This joint probability, displayed in Fig. 10(b), shows that the first shell contains most likely four $\mathrm{Li}^{+}$and no $\mathrm{K}^{+}$, but structures with only three $\mathrm{Li}^{+}$, only five $\mathrm{Li}^{+}$or one $\mathrm{K}^{+}$and three $\mathrm{Li}^{+}$are also significant. Cumulative distribution of residence times for both cations are shown in Fig. 10(c) together with an exponential fit of the long-time tails of the distribution (we disregard the short timescales related to vibrational motions). These distributions reveal different timescales: $\mathrm{Li}^{+}$stays on average 8 ps around $\mathrm{O}^{2-}$, as given by the exponential decay, and up to tens ps for 


\section{$\mathrm{CO}$}
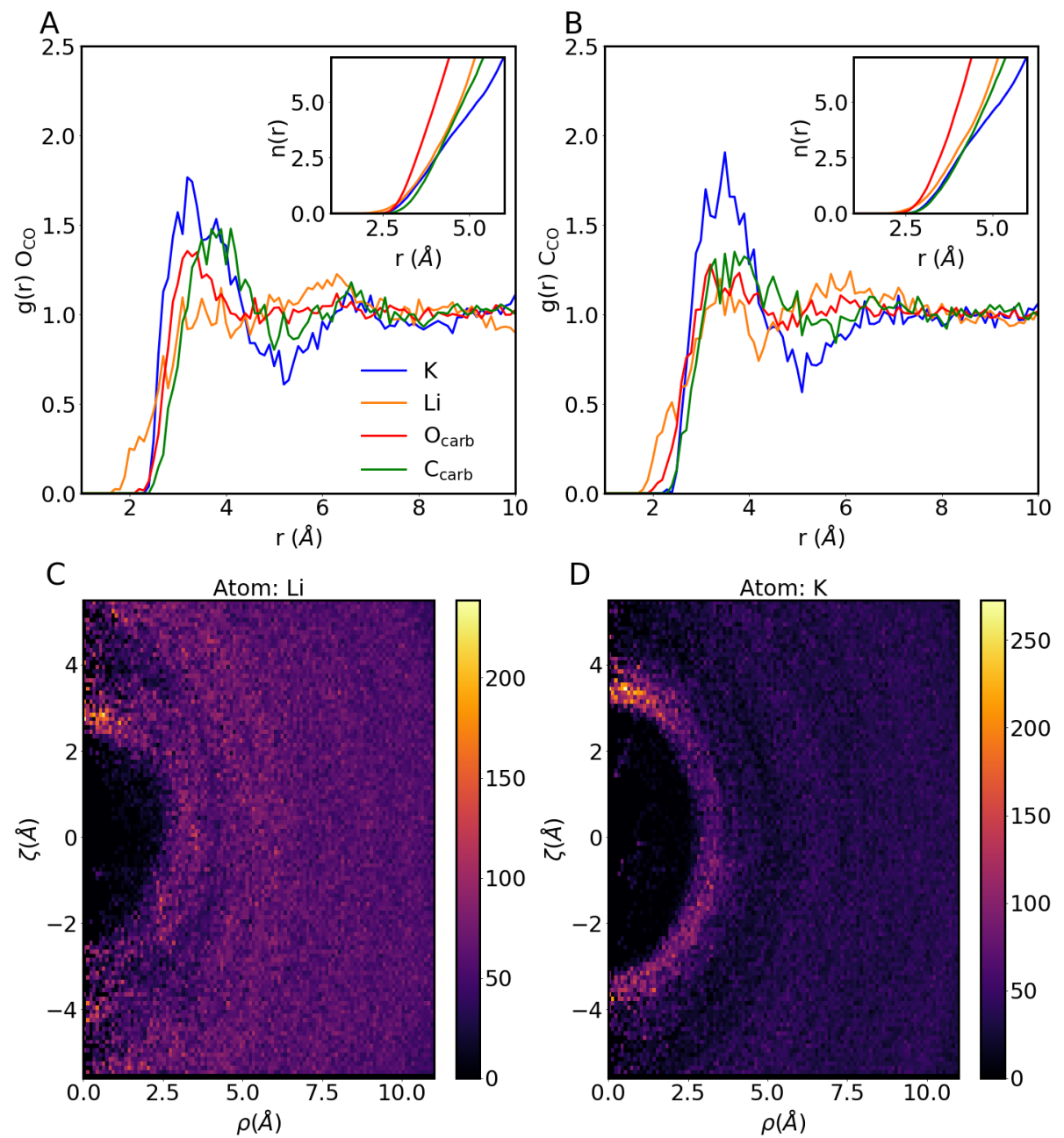

Figure 9: Solvation structure around the carbon monoxide CO. Upper panel: radial distribution function (RDF) for (a) carbon atom of $\mathrm{CO}$ and (b) oxygen atom of CO. Insets: coordination number $n(r)$ obtained from the integration of the radial distribution functions. The same color code applies for figures (a) and (b). Lower panel: two dimensional colour charts representing the probability of the presence of the following atoms around $\mathrm{CO}$ : Li atom (c) and $\mathrm{K}$ atom (d). $\mathrm{CO}$ is oriented with its $\mathrm{O}_{\mathrm{CO}}-\mathrm{C}_{\mathrm{CO}}$ axis along the $\hat{\zeta}$ direction, where $\zeta=0$ is the mid-point of the $\mathrm{O}_{\mathrm{CO}}-\mathrm{C}_{\mathrm{CO}}$ distance and $\mathrm{O}_{\mathrm{CO}}$ is always placed in the negative $\zeta$ portion of the plots. 
some ions. On the opposite, the presence of $\mathrm{K}^{+}$is more short-lived with an exponential decay time of $1.5 \mathrm{ps}$. From the RDFs, the coordination number, the joint distribution and the residence time, a picture emerges of a transient complex $\mathrm{OLi}_{4}^{2+}$ with fast entrance/exit of $\mathrm{K}^{+}$. We explore the internal structure of this complex by looking at the distribution of Li-O-Li, Li-O-K and K-O$\mathrm{K}$ angles (shown in Fig. 10(d)). These angles distributions peak around $90^{\circ}$ and $180^{\circ}$ with minima around $125^{\circ}$ and the ratio between the highest and lowest probability is only a factor 2 . These results indicate that (i) tetrahedral configurations are not predominant and (ii) the structure of the complex is flexible with many configurations possible. To summarize our analysis of the solvation of $\mathrm{O}^{2-}$, we have shown the existence of a transient complex $\mathrm{OLi}_{4}^{2+}$ of electrochemical relevance, rather than the isolated $\mathrm{O}^{2-}$ anion. This complex displays a flexible structure, easily distorted by the fast entrance/exit of $\mathrm{K}^{+}$ within the first solvation shell.

\subsection{Diffusion and Rotation}

We now conclude the analysis of these solvated species in $\mathrm{LiKCO}_{3}$ by investigating two dynamical properties: the translational diffusion in the liquid and the reorientation of these molecules.

The diffusion of these species within the molten carbonate medium - to and from the electrodes - is an essential step in the electrochemical processes of $\mathrm{MCFC} / \mathrm{MCEC}$, but the values of diffusion coefficient are often difficult to obtain experimentally. In MD simulations, the diffusion coefficient of a given molecule is obtained by taking the slope of the mean-square displacement (MSD) at long time, $D_{I}=\lim _{\tau \rightarrow \infty} \frac{1}{6} \frac{\mathrm{dMSD}_{I}(\tau)}{\mathrm{d} \tau}$, with $\operatorname{MSD}_{I}(\tau)=\left\langle\left|\mathbf{R}_{I}(\tau)-\mathbf{R}_{I}(0)\right|^{2}\right\rangle$ and where $\mathbf{R}_{I}(t)$ is the center-of-mass of molecule $I$ at time $t$ and the bracket represents an average over time. We applied this MSD definition for $\mathrm{C}_{2} \mathrm{O}_{4}^{2-}, \mathrm{CO}, \mathrm{O}^{2-}$ as well as the solvent molecules, but we must take a special care in the case of the reactive $\mathrm{CO}_{2}$. We adapt the definition of the MSD to integrate the transient nature of $\mathrm{CO}_{2}$ and the variable index of its constituent atoms,

$$
\operatorname{MSD}_{\mathrm{CO}_{2}}(\tau)=\frac{\sum_{t=1}^{N_{\text {steps }}}|\mathbf{R}(t+\tau)-\mathbf{R}(t)|^{2} \chi_{t} \chi_{t+\tau}}{\sum_{t=1}^{N_{\text {steps }}} \chi_{t} \chi_{t+\tau}}
$$

where the characteristic function $\chi_{t}=1$ if $\mathrm{CO}_{2}$ is present at time $t$ and $\chi_{t}=0$ otherwise. Fig. 11(a) shows the MSDs vs time for the four solvated species and the linear functions fitted on the MSDs to extract the diffusion coefficients. The latter are summarized in Table 2 together with the diffusion coefficient for the three ionic species that composed the solvent. The diffusion coefficient range from 0.5 to $4 \cdot 10^{-5} \mathrm{~cm}^{2} \cdot \mathrm{s}^{-1}$, where the highest diffusion coefficient is found for $\mathrm{CO}$. We explain this feature of $\mathrm{CO}$ by noting that $\mathrm{CO}$ is a neutral molecule, with a small electrostatic dipole $\left(p_{\mathrm{CO}}=0.11 \mathrm{D}\right)$, a relatively small size and a near spherical shape. These features indicates that $\mathrm{CO}$ interacts only weakly with the surrounding molten carbonate and behaves probably similarly to a noble gas that can diffuse quickly in the liquid. The second highest diffusion coefficient is 
A

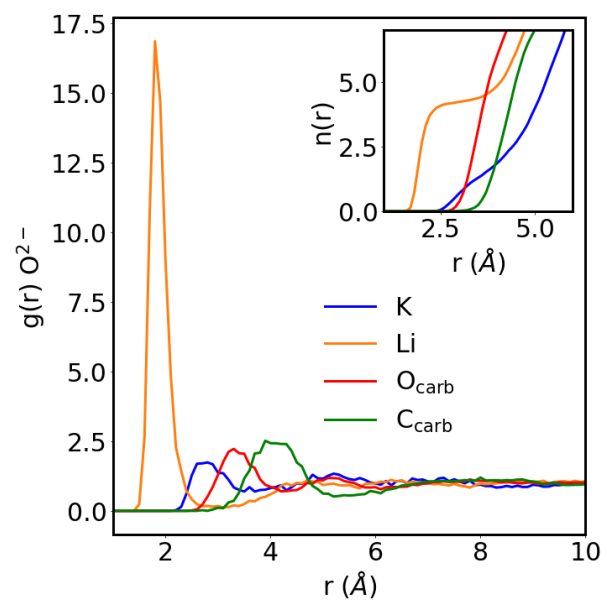

C

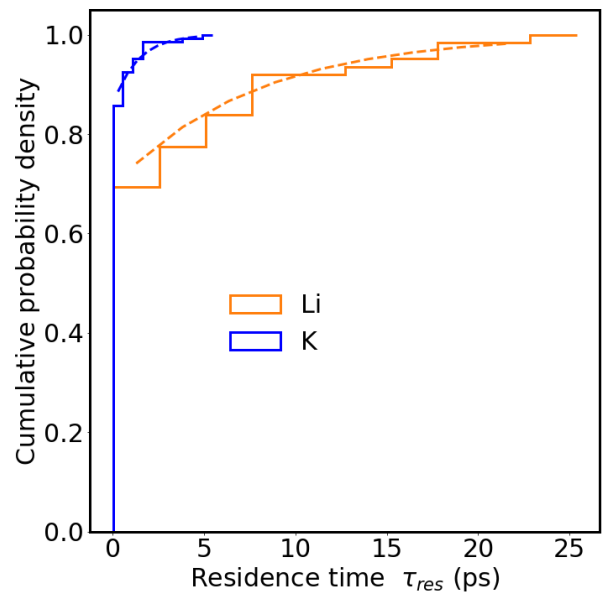

B

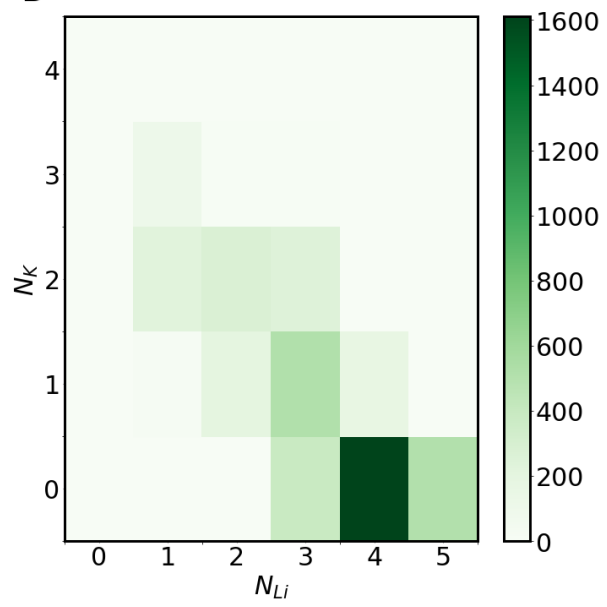

$\mathrm{D}$

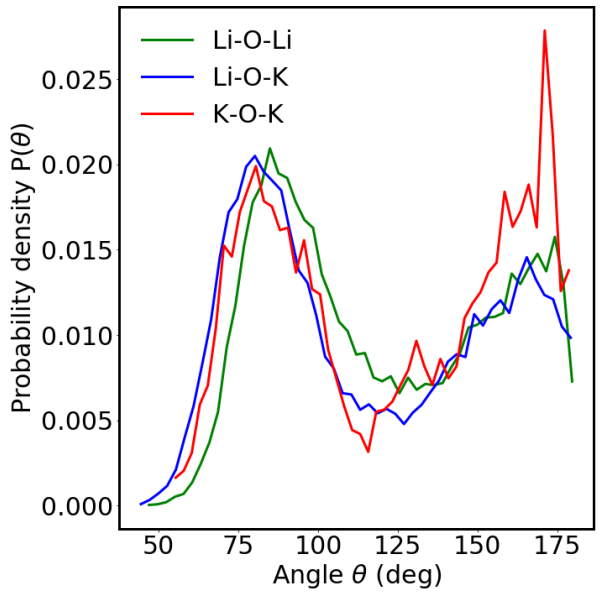

Figure 10: (a) Radial distribution function (RDF) for oxygen anion $\mathrm{O}^{2-}$. Insets: coordination number $n(r)$ obtained from the integration of the radial distribution functions. (b) Distribution of the joint probability of presence of lithium and potassium cations within the first solvation shell of (defined with distance O-Li $<3.1 \AA$ and distance $\mathrm{O}-\mathrm{K}<3.6 \AA$ ). (c) Cumulative residence time $\tau_{\text {res }}$ distribution of lithium and potassium cations and exponential fit for the long-tail of these distributions (dashed lines). (d) Distribution of Li-O-Li angle for lithium cations within the first solvation shell of $\mathrm{O}^{2-}$. The distribution is normalized by dividing by $\sin \theta$. 
that of the $\mathrm{CO}_{2}$ species. The MSD for $\mathrm{CO}_{2}$ (eq. 6) takes into account its reactivity and the displacement induced by the successive formation and dissociation of pyrocarbonate. If $\mathrm{CO}_{2}$ shares some similarity with $\mathrm{CO}$ (a neutral molecule with a small dipole moment), its interaction with the solvent is stronger, in particular with the carbonate anion $\mathrm{CO}_{3}^{2-}$ that forms a preferential structure as discussed in section 3.2.1. The smallest diffusion coefficient is that of the oxygen anion $\mathrm{O}^{2-}\left(0.54 \cdot 10^{-5} \mathrm{~cm}^{2} \cdot \mathrm{s}^{-1}\right)$. As described in section 3.2.5, this divalent anion strongly attracts four lithium ions to form a relatively stable $\mathrm{OLi}_{4}^{2+}$ complex that could explain its slow diffusivity due its larger size and bulkier nature. We also note that the diffusion coefficient of the solvent molecules are three times smaller than the one measured experimentally at $1100 \mathrm{~K}[36]\left(3.52 \cdot 10^{-5} \mathrm{~cm}^{2}\right.$ for $\mathrm{CO}_{3}^{2-}$ and $3.81 \cdot 10^{-5} \mathrm{~cm}^{2}$ for $\mathrm{K}^{+}$), but they correspond to the calculated diffusion coefficient from MD simulations in the $1100 \mathrm{~K}$ to $1200 \mathrm{~K}$ temperature range [16, 37-39] $\left(0.55-1.9 \cdot 10^{-5} \mathrm{~cm}^{2}, 2.55-5.38 \cdot 10^{-5} \mathrm{~cm}^{2}\right.$ and $1.55-4.99 \cdot 10^{-5} \mathrm{~cm}^{2}$ for $\mathrm{CO}_{3}^{2-}, \mathrm{Li}^{+}$and $\mathrm{K}^{+}$respectively).

We then analysed our simulations to obtain information on the reorientation of these species in the molten carbonate, a property that could be more easily measured experimentally and may bring information on their diffusion mechanism. We quantified the reorientation process in our MD simulations using the second-order reorientation time-correlation function,

$$
\begin{array}{cc}
C_{2}(t) \quad & \left\langle P_{2}[\mathbf{u}(t) \cdot \mathbf{u}(0)]\right\rangle \\
=\left\langle\frac{1}{2}\left(3|\mathbf{u}(t) \cdot \mathbf{u}(0)|^{2}-1\right)\right\rangle
\end{array}
$$

where $P_{2}$ is the second-order Legendre polynomial and $\mathbf{u}$ is a normalized vector characterizing the orientation of the molecule (we choose the vector between $\mathrm{O}$ atoms for $\mathrm{CO}_{2}$, between $\mathrm{C}$ atoms for $\mathrm{C}_{2} \mathrm{O}_{5}^{2-}$ and $\mathrm{C}_{2} \mathrm{O}_{4}^{2-}$ and between $\mathrm{C}$ and $\mathrm{O}$ atoms for CO). Fig. 11(b) shows the reorientation time-correlations $C_{2}(t)$ for the different solvated molecules, as well as an exponential-fitted decay (of the form $\left.A \exp \left(-t / \tau_{\text {reor }}\right)\right)$ of $C_{2}(t)$. The reorientation times obtained from the fit, $\tau_{\text {reor }}$, are gathered in table 2 for the different solvated molecules and for the solvent anion $\mathrm{CO}_{3}^{2-}$. Except for the particular case of $\mathrm{CO}$ molecule $\left(\tau_{\text {reor }}=0.1 \mathrm{ps}\right)$, the reorientation times range between $1.3 \mathrm{ps}$ and 3.4 ps with the following order: $\mathrm{CO}_{3}^{2-}<\mathrm{CO}_{2}<\mathrm{C}_{2} \mathrm{O}_{4}^{2-}<\mathrm{C}_{2} \mathrm{O}_{5}^{2-}$. The short reorientation time of the $\mathrm{CO}$ molecule indicates that it can freely rotate in the molten carbonate and confirms the observation made for the translational diffusion that $\mathrm{CO}$ only weakly interacts with the molten carbonate. In contract, the oxalate and pyrocarbonate anions are charged and relatively large molecules whose reorientation is about 30 times slower than $\mathrm{CO}$.

\section{Conclusion}

We have investigated in this work the solvation properties of key molecules in the operation of MCFC/MCEC in the eutectic $(62 \% 38 \%) \mathrm{LiKCO}_{3}$ using 

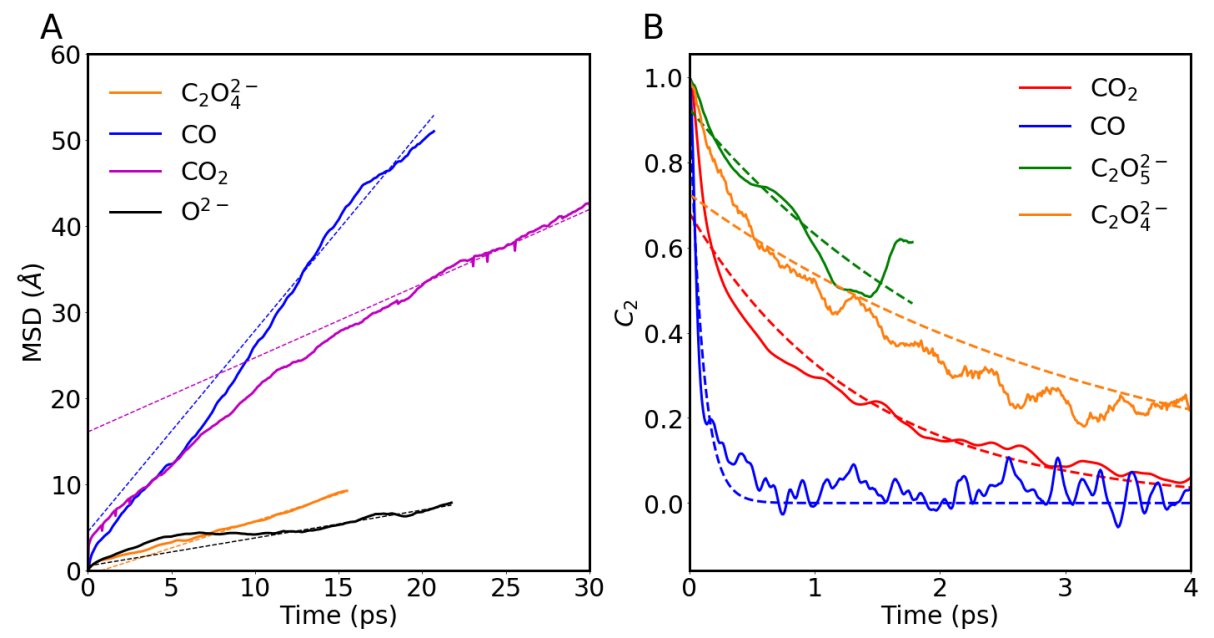

Figure 11: Dynamical properties of the solvated species. (a) Mean-square displacement (MSD) along time. The MSD are fitted to a linear function (dashed lines) to calculate the diffusion coefficient, see Table 2. The MSD for $\mathrm{CO}_{2}$ molecule is calculated between times where the $\mathrm{CO}_{2}$ molecule is present. (b) Reorientation time-correlation functions $C_{2}(t)$ (eq. 8). The $C_{2}(t)$ function are fitted to an exponential decay function to determine the reorientation time, see Table 2 .

Table 2: Dynamical properties of the molecules solvated in the eutectic $\mathrm{LiKCO}_{3}$. The diffusion coefficient is obtained from a linear fitting of the mean-square displacement, and the reorientation time from an exponential fitting of the time-correlation reorientation function (eq. 8).

\begin{tabular}{|c|c|c|}
\hline Molecule & Diffusion coefficient $\left(10^{-5} \mathrm{~cm}^{2} . \mathrm{s}^{-1}\right)$ & Reorientation time $(\mathrm{ps})$ \\
\hline $\mathrm{CO}_{2}$ & 1.4 & 1.4 \\
$\mathrm{C}_{2} \mathrm{O}_{5}^{2-}$ & - & 2.6 \\
$\mathrm{C}_{2} \mathrm{O}_{4}^{2-}$ & 1.0 & 3.4 \\
$\mathrm{CO}$ & 3.9 & 0.1 \\
$\mathrm{O}^{2-}$ & 0.54 & - \\
\hline $\mathrm{CO}_{3}^{2-}$ & 0.69 & 1.3 \\
$\mathrm{Li}^{+}$ & 2.4 & - \\
$\mathrm{K}^{+}$ & 1.4 & - \\
\hline
\end{tabular}


first-principles molecular dynamics. Similar to what happens in molten $\mathrm{CaCO}_{3}$, we find that the solubilized $\mathrm{CO}_{2}$ molecule spontaneously reacts with $\mathrm{CO}_{3}^{2-}$ to form the transient pyrocarbonate species $\mathrm{C}_{2} \mathrm{O}_{5}^{2-}$. The lifetime of the pyrocarbonate anion is however significantly longer in the eutectic $\mathrm{LiKCO}_{3}$ than in $\mathrm{CaCO}_{3}$, possibly because of the lower temperature. In contrast to $\mathrm{CO}_{2} / \mathrm{C}_{2} \mathrm{O}_{5}^{2-}$, both $\mathrm{CO}$ and the oxalate anion, $\mathrm{C}_{2} \mathrm{O}_{4}^{2-}$, are found to be stable in the eutectic $\mathrm{LiKCO}_{3}$. This confirms the oxalate anion as a putative intermediate in the reduction of $\mathrm{CO}_{2}$. Its disproportionation reaction (or inversely its formation) is probably activated as it needs not only the breaking of the $\mathrm{C}-\mathrm{C}$ bond but also the breaking and formation of a C-O bond. Such activated process are unlikely to be observed during the simulation times accessible to our first-principles simulations, and further studies are needed to describe the formation mechanism and thermodynamics of oxalate. Free energy methods could be employed in combination with first-principles molecular dynamics in order to measure these thermodynamics properties.

The study of the solvation structures highlights the different behaviour of $\mathrm{K}^{+}$and $\mathrm{Li}^{+}$in the molten carbonate medium. Because of its smaller size, $\mathrm{Li}^{+}$ binds more strongly to charged species $\left(\mathrm{C}_{2} \mathrm{O}_{5}^{2-}, \mathrm{C}_{2} \mathrm{O}_{4}^{2-}, \mathrm{O}^{2-}\right.$ and $\left.\mathrm{CO}_{3}^{2-}\right)$. $\mathrm{O}^{2-}$ forms in particular a flexible complex with four $\mathrm{Li}^{+} . \mathrm{K}^{+}$is found preferentially around neutral molecules $\left(\mathrm{CO}_{2}\right.$ and $\left.\mathrm{CO}\right)$. These contrasting behaviour regarding solvation between $\mathrm{Li}^{+}$and $\mathrm{K}^{+}$- and their effects on solubility and transport properties - may contribute to the choice of an optimal molten carbonate composition to operate an MCEC process.

Finally, we have estimated the diffusion coefficients of these solvated species, which are important parameters for the interpretation of experimental data and the modelling of MCEC operation. Of all the species studied, CO diffuses significantly faster consistently with its small size and poor interaction with the melt. In the future, we plan to compute other experimental observables allowing for a direct comparison with in situ experiments, such as Raman spectra or NMR chemical shifts. [40]

\section{Acknowledgement}

The authors are grateful to Michel Cassir for discussion on the interesting properties of molten carbonate. We acknowledge funding by PSL Research University (project COOCAR, grant ANR-10-IDEX-0001-02) and from

the French Agence Nationale de la Recherche (ANR) under grant ANR-17CE05-0025 (MCEC) . This work was performed using HPC resources from GENCI (grants A0030802309 and A0050802309).

[1] S. Frangini, A. Massi, Molten carbonates for advanced and sustainable energy applications: Part II. Review of recent literature, International Journal of Hydrogen Energy 41 (42) (2016) 18971-18994. doi:10.1016/j.ijhydene.2016.08.076. 
[2] M. Cassir, S. McPhail, A. Moreno, Strategies and new developments in the field of molten carbonates and high-temperature fuel cells in the carbon cycle, International Journal of Hydrogen Energy 37 (24) (2012) 1934519350. doi:10.1016/j.ijhydene.2011.11.006.

[3] S. Campanari, P. Chiesa, G. Manzolini, $\mathrm{CO}_{2}$ capture from combined cycles integrated with Molten Carbonate Fuel Cells, International Journal of Greenhouse Gas Control 4 (3) (2010) 441-451. doi:10.1016/j.ijggc.2009.11.007.

[4] D. Chery, V. Lair, M. Cassir, Overview on $\mathrm{CO}_{2}$ valorization: challenge on molten carbonate, Front. Energy Res., 3 (43) (2015) doi:10.3389/fenrg.2015.00043.

[5] L. Mastropasqua, L. Pierangelo, M. Spinelli, M. C. Romano, S. Campanari, S. Consonni, Molten Carbonate Fuel Cells retrofits for $\mathrm{CO}_{2}$ capture and enhanced energy production in the steel industry, International Journal of Greenhouse Gas Control 88 (2019) 195-208. doi:10.1016/j.ijggc.2019.05.033.

[6] L. Hu, I. Rexed, G. Lindbergh, C. Lagergren, Electrochemical performance of reversible molten carbonate fuel cells, International Journal of Hydrogen Energy 39 (23) (2014) 12323-12329. doi:10.1016/j.ijhydene.2014.02.144.

[7] D. Chery, V. Albin, V. Lair, M. Cassir, Thermodynamic and experimental approach of electrochemical reduction of $\mathrm{CO}_{2}$ in molten carbonates, International Journal of Hydrogen Energy 39 (23) (2014) 12330-12339 doi:10.1016/j.ijhydene.2014.03.113.

[8] D. Chery, V. Lair, M. Cassir, $\mathrm{CO}_{2}$ electrochemical reduction into $\mathrm{CO}$ and $\mathrm{C}$ in molten carbonates: a thermodynamic point of view, Electrochimica Acta, 160 (43) (2015) 74-81 doi:10.1016/j.electacta.2015.01.216.

[9] L. Hu, G. Lindbergh, C. Lagergren, Electrode kinetics of the $\mathrm{NiO}$ porous electrode for oxygen production in the molten carbonate electrolysis cell (MCEC), Faraday Discuss. 182 (2015) 493-50. doi:/doi.org/10.1039/c5fd00011d.

[10] L. Hu, G. Lindbergh, C. Lagergren, Performance and Durability of the Molten Carbonate Electrolysis Cell and the Reversible Molten Carbonate Fuel Cell, The Journal of Physical Chemistry C 120 (25) (2016) 1342713433. doi:10.1021/acs.jpcc.6b04417.

[11] V. Kaplan, E. Wachtel, K. Gartsman, Y. Feldman, I. Lubomirsky, Conversion of $\mathrm{CO}_{2}$ to $\mathrm{CO}$ by Electrolysis of Molten Lithium Carbonate, Journal of The Electrochemical Society 157 (4) (2010) B552-B556. doi:10.1149/1.3308596. 
[12] D. Chery, V. Albin, A. Meléndez-Ceballos, V. Lair, M. Cassir, Mechanistic approach of the electrochemical reduction of $\mathrm{CO}_{2}$ into $\mathrm{CO}$ at a gold electrode in molten carbonates by cyclic voltammetry, International Journal of Hydrogen Energy 41 (41) (2016) 18706-18712. doi:10.1016/j.ijhydene.2016.06.094.

[13] H. Meskine, E. Gürbüz, V. Albin, A. Meléndez-Ceballos, M. Cassir, A. Ringuedé, V. Lair, $\mathrm{CO}_{2}$ electrolysis in a reversible molten carbonate fuell cell: Online chromatographic detection of CO, International Journal of Hydrogen Energy $\mathrm{xx}$ ( $\mathrm{xx}$ ) ( $\mathrm{xxxx}$ ) $\mathrm{xxxxx}-\mathrm{xxxxx}$ doi:10.1016/j.ijhydene.2020.08.028.

[14] R. Vuilleumier, A. Seitsonen, N. Sator, B. Guillot, Structure, equation of state and transport properties of molten calcium carbonate $\left(\mathrm{CaCO}_{3}\right)$ by atomistic simulations, Geochimica et Cosmochimica Acta 141 (2014) 547566. doi:10.1016/j.gca.2014.06.037.

[15] D. Corradini, F.-X. Coudert, R. Vuilleumier, Carbon dioxide transport in molten calcium carbonate occurs through an oxo-Grotthuss mechanism via a pyrocarbonate anion, Nature Chemistry. doi:10.1038/nchem.2450.

[16] D. Corradini, F.-X. Coudert, R. Vuilleumier, Insight into the $\mathrm{Li}_{2} \mathrm{CO}_{3}$ $\mathrm{K}_{2} \mathrm{CO}_{3}$ eutectic mixture from classical molecular dynamics: Thermodynamics, structure, and dynamics, The Journal of Chemical Physics 144 (10) (2016) 104507. doi:10.1063/1.4943392.

[17] M. Wilson, M. C. C. Ribeiro, M. C. Wilding, C. Benmore, J. K. R. Weber, O. Alderman, A. Tamalonis, J. B. Parise, Structure and Liquid Fragility in Sodium Carbonate, The Journal of Physical Chemistry A 122 (4) (2018) 1071-1076. doi:10.1021/acs.jpca.7b10712.

[18] A. Gutiérrez, S. Garroni, S. Souentie, S. Cuesta-López, I. Yakoumis, S. Aparicio, Theoretical Study on Molten Alkali Carbonate Interfaces, Langmuir 34 (43) (2018) 13065-13076. doi:10.1021/acs.langmuir.8b02907.

[19] E. Desmaele, N. Sator, R. Vuilleumier, B. Guillot, Atomistic simulations of molten carbonates: Thermodynamic and transport properties of the $\mathrm{Li}_{2} \mathrm{CO}_{3}-\mathrm{Na}_{2} \mathrm{CO}_{3}-\mathrm{K}_{2} \mathrm{CO}_{3}$ system, The Journal of Chemical Physics 150 (9) (2019) 094504. doi:10.1063/1.5082731.

[20] E. Desmaele, N. Sator, R. Vuilleumier, B. Guillot, The $\mathrm{MgCO}_{3}-\mathrm{CaCO}_{3}-$ $\mathrm{Li}_{2} \mathrm{CO}_{3}-\mathrm{Na}_{2} \mathrm{CO}_{3}-\mathrm{K}_{2} \mathrm{CO}_{3}$ melts: Thermodynamics and transport properties by atomistic simulations, The Journal of Chemical Physics 150 (21) (2019) 214503. doi:10.1063/1.5099015.

[21] R. Car, M. Parrinello, Unified Approach for Molecular Dynamics and Density-Functional Theory, Physical Review Letters 55 (22) (1985) 24712474. doi:10.1103/PhysRevLett.55.2471. 
[22] Y. Kono, C. Kenney-Benson, D. Hummer, H. Ohfuji, C. Park, G. Shen, Y. Wang, A. Kavner, C. E. Manning, Ultralow viscosity of carbonate melts at high pressures, Nature Communications 5. doi:10.1038/ncomms6091.

[23] G. Janz, Thermodynamic and transport properties for molten salts: correlation equations for critically evaluated density, surface tension, electrical conductance and viscosity data, J. Phys. Chem. Ref. Data 17 (Suppl. 2) (1988).

[24] G. Bussi, D. Donadio, M. Parrinello, Canonical sampling through velocity rescaling, The Journal of Chemical Physics 126 (1) (2007) 014101. doi: $10.1063 / 1.2408420$.

[25] B. G. Lippert, J. Hutter, M. Parrinello, A hybrid Gaussian and plane wave density functional scheme, Molecular Physics 92 (3) (1997) 477-488. doi:10.1080/002689797170220.

[26] J. VandeVondele, M. Krack, F. Mohamed, M. Parrinello, T. Chassaing, J. Hutter, Quickstep: Fast and accurate density functional calculations using a mixed Gaussian and plane waves approach, Computer Physics Communications 167 (2) (2005) 103-128. doi:10.1016/j.cpc.2004.12.014.

[27] J. Hutter, M. Iannuzzi, F. Schiffmann, J. VandeVondele, CP2K: atomistic simulations of condensed matter systems, Wiley Interdisciplinary Reviews: Computational Molecular Science 4 (1) (2014) 15-25. doi:10.1002/wcms.1159.

[28] S. Goedecker, M. Teter, J. Hutter, Separable dual-space Gaussian pseudopotentials, Physical Review B 54 (3) (1996) 1703-1710. doi:10.1103/PhysRevB.54.1703.

[29] C. Hartwigsen, S. Goedecker, J. Hutter, Relativistic separable dual-space Gaussian pseudopotentials from H to Rn, Physical Review B 58 (7) (1998) 3641-3662. doi:10.1103/PhysRevB.58.3641.

[30] M. Krack, Pseudopotentials for $\mathrm{H}$ to Kr optimized for gradient-corrected exchange-correlation functionals, Theoretical Chemistry Accounts 114 (1) (2005) 145-152. doi:10.1007/s00214-005-0655-y.

[31] J. VandeVondele, J. Hutter, Gaussian basis sets for accurate calculations on molecular systems in gas and condensed phases, The Journal of Chemical Physics 127 (11) (2007) 114105. doi:10.1063/1.2770708.

[32] A. D. Becke, Density-functional exchange-energy approximation with correct asymptotic behavior, Physical Review A 38 (6) (1988) 3098-3100. doi:10.1103/PhysRevA.38.3098.

[33] C. Lee, W. Yang, R. G. Parr, Development of the Colle-Salvetti correlationenergy formula into a functional of the electron density, Physical Review B 37 (2) (1988) 785-789. doi:10.1103/PhysRevB.37.785. 
[34] S. Grimme, Semiempirical GGA-type density functional constructed with a long-range dispersion correction, Journal of Computational Chemistry 27 (15) (2006) 1787-1799. doi:10.1002/jcc.20495.

[35] D. Laage, J. T. Hynes, A Molecular Jump Mechanism of Water Reorientation, Science 311 (5762) (2006) 832-835. doi:10.1126/science.1122154.

[36] G. J. Janz, N. P. Bansal, Molten Salts Data: Diffusion Coefficients in Single and Multi-Component Salt Systems, Journal of Physical and Chemical Reference Data 11 (3) (1982) 505-693. doi:10.1063/1.555665.

[37] J. T. W. M. Tissen, G. J. M. Janssen, P. v. d. Eerden, Molecular dynamics simulation of binary mixtures of molten alkali carbonates, Molecular Physics 82 (1) (1994) 101-111. doi:10.1080/00268979400100084.

[38] T. Koishi, S. Kawase, S. Tamaki, T. Ebisuzaki, Computer Simulation of Molten $\mathrm{Li}_{2} \mathrm{CO}_{3}-\mathrm{K}_{2} \mathrm{CO}_{3}$ Mixtures, Journal of the Physical Society of Japan 69 (10) (2000) 3291-3296. doi:10.1143/JPSJ.69.3291.

[39] M. F. Costa, Molecular dynamics of molten $\mathrm{Li}_{2} \mathrm{CO}_{3}-\mathrm{K}_{2} \mathrm{CO}_{3}$, Journal of Molecular Liquids 138 (1) (2008) 61-68. doi:10.1016/j.molliq.2007.08.001.

[40] Y. Morizet, R. Vuilleumier, M. Paris, A NMR and molecular dynamics study of $\mathrm{CO}_{2}$-bearing basaltic melts and glasses, Chemical Geology. 